\title{
Adaptive Second Order Sliding Mode Control of a Fuel Cell Hybrid System for Electric Vehicle Applications
}

\author{
Jianxing Liu, ${ }^{1}$ Yue Zhao, ${ }^{1}$ Bo Geng, $^{2}$ and Bing Xiao ${ }^{3}$ \\ ${ }^{1}$ Control Science and Engineering, Harbin Institute of Technology, Harbin 150000, China \\ ${ }^{2}$ Department of Electrical and Computer Engineering, University of Texas, Austin, TX 78712, USA \\ ${ }^{3}$ College of Engineering, Bohai University, Jinzhou 121013, China
}

Correspondence should be addressed to Yue Zhao; zhaoyuelj@163.com

Received 14 June 2014; Accepted 13 July 2014

Academic Editor: Ligang Wu

Copyright (C) 2015 Jianxing Liu et al. This is an open access article distributed under the Creative Commons Attribution License, which permits unrestricted use, distribution, and reproduction in any medium, provided the original work is properly cited.

\begin{abstract}
We present an adaptive-gain second order sliding mode (SOSM) control applied to a hybrid power system for electric vehicle applications. The main advantage of the adaptive SOSM is that it does not require the upper bound of the uncertainty. The proposed hybrid system consists of a polymer electrolyte membrane fuel cell (PEMFC) with a unidirectional DC/DC converter and a Li-ion battery stack with a bidirectional DC/DC converter, where the PEMFC is employed as the primary energy source and the battery is employed as the second energy source. One of the main limitations of the FC is its slow dynamics mainly due to the air-feed system and fuel-delivery system. Fuel starvation phenomenon will occur during fast load demand. Therefore, the second energy source is required to assist the main source to improve system perofrmance. The proposed energy management system contains two cascade control structures, which are used to regulate the fuel cell and battery currents to track the given reference currents and stabilize the DC bus voltage while satisfying the physical limitations. The proposed control strategy is evaluated for two real driving cycles, that is, Urban Dynamometer Driving Schedule (UDDS) and Highway Fuel Economy Driving Schedule (HWFET).
\end{abstract}

\section{Introduction}

Polymer electrolyte membrane fuel cells (PEMFCs) have emerged as the most prominent technology for energizing future's automotive world. They are clean, quiet, and efficient and have been widely studied in automotive applications over the past two decades due to their relatively small size, light weight, and easy manufacturing [1-3]. Despite these advantages, there are still major issues concerning cost, liability, and durability to be addressed before they become a widely used alternative to internal combustion engines.

One of the main drawbacks of the FCs is slow dynamics dominated by the air-supply system and fuel-delivery system. As a result, the FCs cannot properly respond to rapid load changes in vehicle power demand which will cause a high voltage drop in a short time recognized as a fuel-starvation phenomenon [4]. Therefore, an additional energy storage system, such as Lithium ion (Li-ion) batteries, is usually used to improve the slow response dynamics of the PEMFC. The PEMFC hybrid electric vehicle (HEV) with Liion battery storage possesses the advantages of the PEMFC and Li-ion battery stack (large energy and power capacities). The PEMFC provides the main power requirements during normal driving condition, while the Li-ion battery stack discharges or stores energy to assist the PEMFC to meet peak power demand. Previous research works have shown that hybridization of FC vehicles with batteries provides the benefits of cost and performance as well as fuel economy $[5,6]$.

In order to achieve the optimal operation performance of the hybrid system, suitable model and controller development efforts are needed [7-13]. In the hybrid configuration, the DC/DC converters adapt the voltage of the fuel cell and the battery to the DC bus voltage. This allows an active control of the power sharing between each source. Therefore, a power management strategy is needed to determine this power 
sharing while respecting system constraints (e.g., battery state of charge (SOC) limits, power limits, etc.) [14-16]. In [17], a load sharing algorithm using fuzzy logic control was studied for a fuel cell/supercapacitor HEV. In [18], a fuel cell/battery/supercapacitor hybrid bus was studied by a fuzzy power management controller, with the effectiveness of the fuzzy controller demonstrated by some designed tests. Recently, energy management based on proportional-integral (PI) controllers have been proposed $[6,19]$. Although PI controllers are easy to be tuned on-line which provide a practical solution to many applications, they can not be robust and reliable in the presence of disturbances or uncertainties.

Sliding mode technique is known for its insensitivity to external disturbance due to operating conditions, high accuracy, and finite time convergence [20-24]. Sliding mode control (SMC) has found wide applications in various dynamical systems, such as stochastic systems [25], Markovian jumping systems [26, 27], and fuzzy systems [28, 29]. However, the main drawback of SMC is the so-called chattering phenomenon [30]. Adaptive sliding mode has been proven to be an efficient solution which does not require the bound of uncertainties [31-33]. The control gains are adapted dynamically to counteract the uncertainties/perturbations, which ensure the sliding mode. To the best of the authors' knowledge, it is the first attempt to apply the adaptive SOSM control to the application of HEV. In this paper, we have proposed a cascade control strategy for the FC hybrid system, using an adaptive-gain super twisting algorithm (ASTW) [31]. The gains of this algorithm are adapted dynamically which ensures the convergence of the tracking error in finite time, without a priori knowledge of the upper bound of uncertainties and perturbations. A state based control algorithm is proposed to generate the power reference for the fuel cell stack. In addition, controllers are also designed for the fuel cell and battery converters to track the given current references and stabilize the DC bus voltage.

The rest of the paper is divided as follows: the modelling of the FC hybrid system is given in Section 2. Section 3 discusses the designs of the power management control strategy, which generates the reference power for the FC. Then, the control strategies for the FC and battery converters using the proposed algorithm are provided. In Section 4, simulation results are given for two real driving cycles, UDDS and HWFET. Finally, the major conclusions are presented in Section 5 .

\section{Model of the Hybrid Fuel Cell Power System}

Figure 1 shows the schema of the studied hybrid system for the vehicle applications. The hybrid system is composed of the PEMFC, the Li-ion battery, FC unidirectional DCDC converter, battery bidirectional DC/DC converter, and tracking motor.

2.1. Fuel Cell System Modelling. In this paper, a $30 \mathrm{~kW}$ fuel cell composed of 90 cells in series is modeled considering its dynamics [34]. The fuel cell behavior is highly nonlinear and is dependent on several variables such as current density, stack temperature, membrane humidity, and reactant partial pressures. Several assumptions are considered: (1) the stack temperature and humidity in the fuel cell cathode are well controlled; (2) the water inside the cathode is only in vapor phase and any extra water in liquid phase is removed from the channels; (3) the input reactant flows are humidified in a consistent and rapid way and the high pressure compressed hydrogen is available; (4) the anode pressure is well controlled to follow the cathode pressure; and (5) the current dynamics of the motor which directly drives the compressor is negligible due to its small time constant as compared to the mechanical dynamics [35].

2.1.1. Fuel Cell Stack Voltage. A single fuel cell operating voltage can be modeled as

$$
V_{\mathrm{fc}}=\left(E-v_{\mathrm{act}}-v_{\mathrm{ohm}}-v_{\text {conc }}\right),
$$

where $E$ is the open circuit voltage and $v_{\text {act }}, v_{\text {ohm }}$, and $v_{\text {conc }}$ present the activation loss, ohmic loss, and concentration loss, respectively.

The open circuit voltage $E$ is expressed as

$$
\begin{aligned}
E= & 1.229-0.85 \cdot 10^{-3}\left(T_{\mathrm{fc}}-298.15\right) \\
& +4.3085 \cdot 10^{-5} T_{\mathrm{fc}}\left[\ln \left(p_{\mathrm{H}_{2}}\right)+\frac{1}{2} \ln \left(p_{\mathrm{O}_{2}}\right)\right],
\end{aligned}
$$

where $T_{\mathrm{fc}}$ is the fuel cell stack temperature and $p_{\mathrm{H}_{2}}, p_{\mathrm{O}_{2}}$ are the partial pressures of hydrogen and oxygen, respectively [34].

The activation loss $v_{\text {act }}$, ohmic loss $v_{\text {ohm }}$, and concentration loss $v_{\text {conc }}$ are expressed as follows.

(1) $v_{\text {act }}=v_{0}+v_{a}\left(1-e^{-b_{1} i}\right)$ is due to the difference between the velocity of the reactions in the anode and cathode [36], where $i=I_{\mathrm{st}} / A_{\mathrm{fc}}$ is the current density, $I_{\mathrm{st}}$ (A) is the stack current, and $A_{\mathrm{fc}}\left(\mathrm{cm}^{2}\right)$ is the active area. $v_{0}$ (volts) is the voltage drop at zero current density, and $v_{a}$ (volts) and $b_{1}$ are constants that depend on the temperature and the oxygen partial pressure $[37,38]$. The values of $v_{0}, v_{a}$, and $b_{1}$ can be determined from a nonlinear regression of experimental data.

(2) $v_{\mathrm{ohm}}=i R_{\mathrm{ohm}}$ is due to the electrical resistance of the electrodes, and the resistance to the flow of ions through the electrolyte [36]. $R_{\mathrm{ohm}}\left(\Omega \cdot \mathrm{cm}^{2}\right)$ represents the fuel cell internal electrical resistance.

(3) $v_{\text {conc }}=i\left(b_{3}\left(i / i_{\max }\right)\right)^{b_{4}}$ results from the drop in concentration of the reactants due to the consumption in the reaction. $b_{3}, b_{4}$, and $i_{\max }$ are constants that depend on the temperature and the reactant partial pressures. $i_{\max }$ is the current density that generates the abrupt voltage drop. 


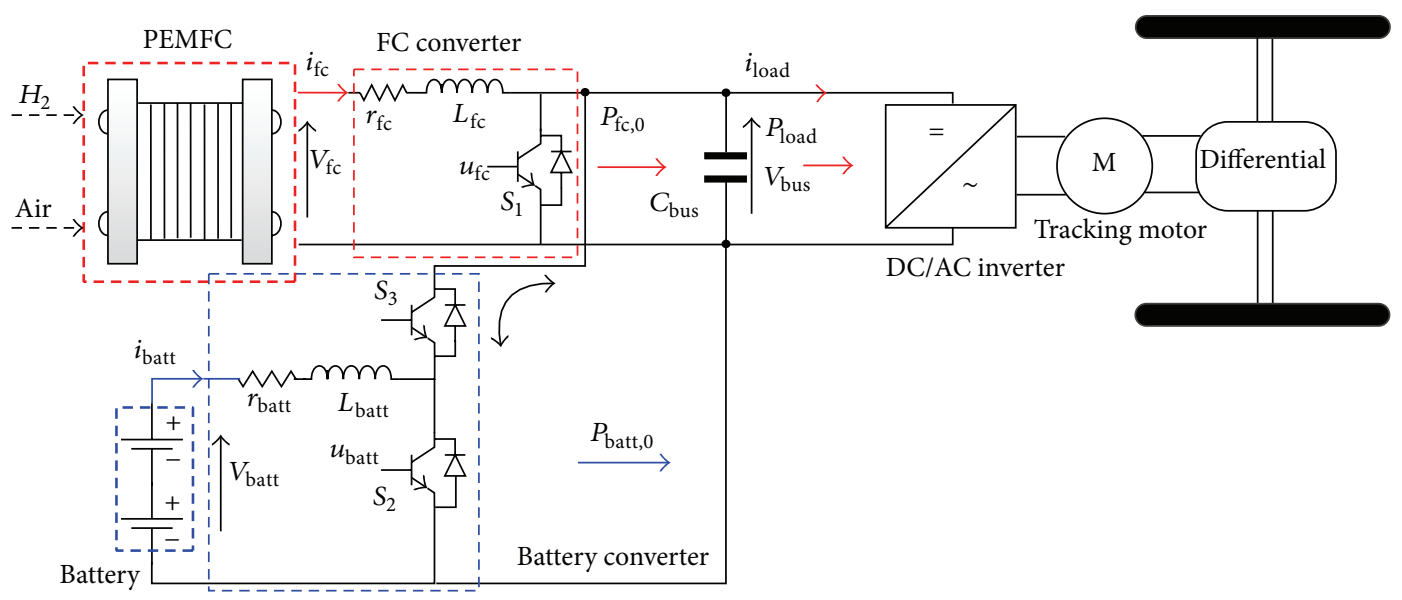

FIGURE 1: Schematic of the fuel cell/battery hybrid power system.

2.1.2. Gas Dynamics of $p_{\mathrm{H}_{2}}$ and $p_{\mathrm{O}_{2}}$. The dynamics of $p_{\mathrm{H}_{2}}, p_{\mathrm{O}_{2}}$ are expressed as follows:

$$
\begin{aligned}
& \frac{d p_{\mathrm{H}_{2}}}{d t}=\frac{R_{\mathrm{H}_{2}} T_{\mathrm{fc}}}{V_{\mathrm{an}}}\left(W_{\mathrm{H}_{2}, \text { in }}-W_{\mathrm{H}_{2}, \text { out }}-W_{\mathrm{H}_{2}, \text { react }}\right), \\
& \frac{d p_{\mathrm{O}_{2}}}{d t}=\frac{R_{\mathrm{O}_{2}} T_{\mathrm{fc}}}{V_{\mathrm{ca}}}\left(W_{\mathrm{O}_{2}, \text { in }}-W_{\mathrm{O}_{2}, \text { out }}-W_{\mathrm{O}_{2}, \text { react }}\right),
\end{aligned}
$$

where $W_{\mathrm{H}_{2} \text {,in }}$ is the mass flow rate of hydrogen gas entering the anode, $W_{\mathrm{H}_{2} \text {,out }}$ is the mass flow rate of hydrogen gas leaving the anode, $W_{\mathrm{H}_{2} \text {,react }}$ is the rate of hydrogen reacted, $W_{\mathrm{O}_{2} \text {, in }}$ is the mass flow rate of oxygen entering the cathode, $W_{\mathrm{O}_{2} \text {,out }}$ is the mass flow rate of oxygen leaving the cathode, $W_{\mathrm{O}_{2} \text {,react }}$ is the rate of oxygen reacted, $R_{\mathrm{H}_{2}}$ is the hydrogen gas constant, $R_{\mathrm{O}_{2}}$ is the oxygen gas constant, and $V_{\text {an }}$ and $V_{\text {ca }}$ are the anode and cathode volumes, respectively. More details are provided in [34].

2.1.3. Thermal Dynamics. The dynamic temperature model is described by a lumped thermal model [39]:

$$
\begin{aligned}
& m_{\mathrm{st}} C_{p_{\mathrm{st}}} \frac{d T_{\mathrm{fc}}}{d t}=\dot{\mathrm{Q}}_{\mathrm{sou}}-W_{c} C_{p_{\mathrm{c}}}\left(T_{\mathrm{fc}}-T_{c, \text { in }}\right), \\
& \dot{\mathrm{Q}}_{\mathrm{sou}}=I_{\mathrm{st}}\left(-\frac{T_{\mathrm{fc}} \Delta s}{4 F}+v_{\mathrm{act}}+I_{\mathrm{st}} R_{\mathrm{ohm}}\right),
\end{aligned}
$$

where $m_{\mathrm{st}}$ is the heat mass of the stack, $C_{p_{\mathrm{st}}}$ and $C_{p_{\mathrm{c}}}$ are the specific heat, $W_{c}$ is the coolant flow rate considered as a control variable, $T_{c \text {,in }}$ is the coolant temperature at the stack inlet, and $\dot{Q}_{\text {sou }}$ is the internal energy source. The latter is calculated as a function of the stack current, temperature, electrical resistance of stack layers $R_{\mathrm{ohm}}$, Faraday's number $F$, and the entropy change $\Delta s$. The physical parameters were obtained through extensive experimentation.

2.1.4. Auxiliary Components. The main power consumer of the fuel cell system is the air compressor, which can consume up to $30 \%$ of the fuel cell power under high load conditions
[40]. Therefore, the net power from the fuel cell system $P_{\mathrm{fc}, \text { net }}$ can be calculated as

$$
P_{\mathrm{fc}, \text { net }}=n V_{\mathrm{fc}} I_{\mathrm{fc}}-P_{\mathrm{cp}}-P_{\mathrm{aux}},
$$

where $n$ is the number of cells and $P_{\mathrm{cp}}$ and $P_{\mathrm{aux}}$ are the power consumed by the compressor and auxiliary components (such as the cooling pump, radiator fan), respectively. In this study, $P_{\mathrm{aux}}$ is assumed to be constant and $P_{\mathrm{cp}}$ is calculated as

$$
P_{\mathrm{cp}}=\frac{C_{p} T_{\mathrm{atm}}}{\eta_{\mathrm{cm}} \eta_{\mathrm{cp}}}\left[\left(\frac{p_{\mathrm{sm}}}{p_{\mathrm{atm}}}\right)^{(\gamma-1) / \gamma}-1\right] W_{\mathrm{cp}},
$$

where $p_{\mathrm{sm}}$ is the supply manifold pressure which is equal to the pressure at the compressor outlet, $p_{\text {atm }}$ is the atmospheric pressure, $C_{p}$ is the specific heat capacity of air, $\gamma$ is the ratio of the specific hears of air, $T_{\text {atm }}$ is the ambient temperature, $W_{\mathrm{cp}}$ is the compressor flow rate, and $\eta_{\mathrm{cm}}$ and $\eta_{\mathrm{cp}}$ are the compressor motor efficiency and compressor efficiency, respectively. Figure 2 shows the efficiency curve of the fuel cell system; it can be found that the optimal operating point is near $8.8 \mathrm{~kW}$.

Remark 1. As discussed in [41], the time constants of the gas dynamics and the stack temperature dynamics are estimated to be the order of magnitude of $10^{-1}$ and $10^{2}$, respectively. Therefore, the mass storage effects in the channels are not considered.

2.2. Fuel Cell Converter Model. A classical boost-type unidirectional DC/DC converter is selected as FC power converter because it can be operated in the current control mode in a continuous condition mode [42]. It adapts the DC voltage supplied by the fc to the desired DC bus voltage $(420 \mathrm{~V})$. By acting on the switching signal $u_{\mathrm{fc}}$, it is possible to determine the load power distribution between FC and battery. The average model of the FC converter is expressed as follows:

$$
L_{\mathrm{fc}} \frac{d i_{\mathrm{fc}}}{d t}=V_{\mathrm{fc}}-r_{\mathrm{fc}} i_{\mathrm{fc}}-u_{\mathrm{fc}} V_{\mathrm{bus}},
$$

where $r_{\mathrm{fc}}$ is the total equivalent series resistance in the FC converter, $u_{\mathrm{fc}}=1-D_{\mathrm{fc}}$, and $D_{\mathrm{fc}}$ is the duty ratio of the switch $S_{1}$. 


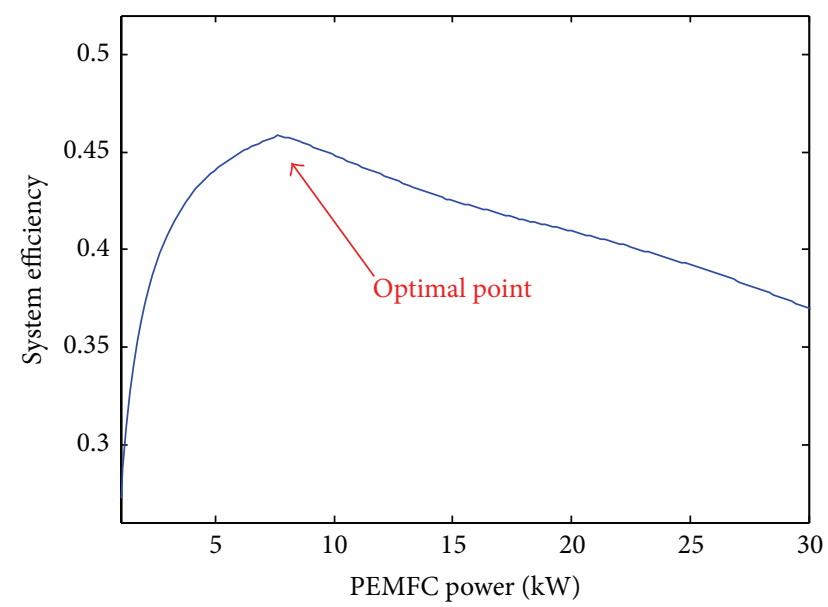

Figure 2: PEMFC efficiency curve.

2.3. Battery Model. The Li-ion battery with peak power $40 \mathrm{~kW}$ and capacity $20 \mathrm{Ah}$ is modeled as a voltage source in series with a resistance $[14,43]$, which is given as

$$
V_{\text {batt }}=V_{\text {oc }}-r_{\text {batt }} i_{\text {batt }}
$$

where the open circuit voltage $\left(V_{\mathrm{oc}}\right)$ and the internal resistance $\left(r_{\text {batt }}\right)$ are both functions of the battery SOC. The SOC is defined as the ratio of charge stored in the battery to the maximum charge capacity $Q_{\text {batt }}$ :

$$
\frac{d \mathrm{SOC}}{d t}=-\frac{i_{\text {batt }}}{Q_{\text {batt }}}
$$

where $i_{\text {batt }}$ is the battery current.

In order to express $i_{\text {batt }}$ it is noted that the instantaneous power delivered by the battery to the load equals $P_{\text {batt }}=$ $V_{\text {batt }} i_{\text {batt }}$. Then, the rate of change of SOC gives

$$
\frac{d \mathrm{SOC}}{d t}=-\frac{V_{\mathrm{oc}}-\sqrt{V_{\mathrm{oc}}^{2}-4 r_{\mathrm{batt}} P_{\mathrm{batt}}}}{2 r_{\mathrm{batt}} Q_{\mathrm{batt}}} .
$$

The solution (10) is feasible for negative power demands which means the battery is in charge mode and maximizes efficiency for positive power demands (discharge mode).

2.4. Battery Converter Model. A simple boost-type bidirectional DC/DC converter is used to connect the battery to the high voltage bus, enabling the charge and discharge of the battery. The cascade control structure of the bidirectional converter is realized through the outer control loop (the DC bus energy loop) and the inner control loop (the battery current loop). The dynamic of the current control loop are designed to be much faster than that of the DC bus energy regulation loop.

The average model of the battery converter is expressed as follows:

$$
L_{\text {batt }} \frac{d i_{\text {batt }}}{d t}=V_{\text {batt }}-r_{\text {batt }} i_{\text {batt }}-u_{\text {batt }} V_{\text {bus }},
$$

TABLE 1: Parameters for the vehicle.

\begin{tabular}{lc}
\hline Parameters & Value \\
\hline Vehicle mass $M$ & $1500 \mathrm{~kg}$ \\
Rolling resistance $C_{r}$ & 0.01 \\
Drag coefficient $C_{D}$ & 0.3 \\
Frontal area $A_{f}$ & $2.4 \mathrm{~m}^{2}$ \\
Air density $\rho_{a}$ & $1.2 \mathrm{~kg} / \mathrm{m}^{3}$ \\
Differential ratio & 5.0 \\
Differential efficiency & $97 \%$ \\
Wheel radius & $0.29 \mathrm{~m}$ \\
\hline
\end{tabular}

where $r_{\text {batt }}$ is the total equivalent series resistance in the battery converter, $u_{\text {batt }}=1-D_{\text {batt }}$, and $D_{\text {batt }}$ is the duty ratio of the switch $S_{2}$.

The DC link capacitive energy $y_{\text {bus }}$ is given versus FC power $P_{\mathrm{fc}}$, battery power $P_{\text {batt }}$, and load power $P_{\text {load }}$ by the following equation:

$$
\dot{y}_{\text {bus }}=P_{\mathrm{fc}, 0}+P_{\text {batt }, 0}-P_{\text {load }},
$$

where $y_{\text {bus }}=(1 / 2) C_{\text {bus }} V_{\text {bus }}^{2}, P_{\mathrm{fc}, 0}=P_{\mathrm{fc}, \text { net }}-r_{\mathrm{fc}} i_{\mathrm{fc}}^{2}$, and $P_{\mathrm{batt}, 0}=$ $P_{\text {batt }}-r_{\text {batt }} i_{\text {batt }}^{2}$.

2.5. Vehicle Dynamics Modelling. The power train is modeled as a point-mass [14]

$$
\begin{aligned}
M \frac{d v}{d t}= & F_{\text {trac }}+F_{\text {brak }}-C_{r} M g \cos \alpha \\
& -\frac{1}{2} \rho_{a} A_{f} C_{D} A_{f} v^{2}-M g \sin \alpha,
\end{aligned}
$$

where $F_{\text {trac }}$ is the vehicle traction force, $F_{\text {brak }}$ is the friction brake force, $M$ is the vehicle mass, $v$ is the vehicle velocity, and other parameters are defined in Table 1.

Then, the power required to drive the tracking motor is calculated as

$$
P_{\text {load }}=F_{\text {trac }} v\left(\eta_{m} \eta_{\text {diff }}\right)^{-\operatorname{sign}\left(F_{\text {trac }}\right)},
$$

where $\eta_{\text {diff }}$ is the efficiency of the differential and $\eta_{m}$ is the efficiency of the tracking motor which is a function of motor torque $\tau_{m}$ and its rotation speed $\omega_{m}$, that is, $\eta_{m}=\eta\left(\tau_{m}, \omega_{m}\right)$.

In the next section, the control strategy of FC and battery will be presented using super-twisting sliding mode.

\section{Energy Management System}

The energy management system implemented is based on the states based control algorithm and a SOSM control which generate the FC and battery reference currents, respectively. Then, the FC and battery current controls are realized with SOSM controllers due to its insensitivity to external disturbance, high accuracy, and finite time convergence. In this paper, the EMS are considered and designed based on the requirements given in Table 2 .

Note that FC has a slow dynamic response, so that the battery functions to compensate the FC dynamic performance to 
TABLE 2: EMS design requirements.

\begin{tabular}{lc}
\hline Fuel cell parameters & \\
\hline$P_{\mathrm{fc}_{\min }}$ & $2 \mathrm{~kW}$ \\
$P_{\mathrm{fc}_{\mathrm{opt}}}$ & $13 \mathrm{~kW}$ \\
$P_{\mathrm{fc}_{\max }}$ & $30 \mathrm{~kW}$ \\
$i_{\mathrm{fc}_{\min }}$ & $2 \mathrm{~A}$ \\
$i_{\mathrm{fc}_{\max }}$ & $300 \mathrm{~A}$ \\
$\tau_{\mathrm{fc}}$ & $0.25 \mathrm{~s}$ \\
$L_{\mathrm{fc}}$ & $2 \cdot 10^{-3} \mathrm{H}$ \\
$r_{\mathrm{fc}}$ & $0.1 \Omega$ \\
FC current dynamic limitation & $40 \mathrm{~A} / \mathrm{s}$ \\
\hline Battery parameters & \\
\hline$P_{\text {batt }}$ & $-40 \mathrm{~kW}$ \\
$P_{\text {batt }}$ & $40 \mathrm{~kW}$ \\
SOC & $30 \%$ \\
SOC & $90 \%$ \\
$L_{\text {batt }}$ & $2 \cdot 10^{-3} \mathrm{H}$ \\
$r_{\text {batt }}$ & $0.1 \Omega$ \\
$V_{\text {bus }}^{*}$ & $420 \mathrm{~V}$ \\
\hline
\end{tabular}

avoid the FC starvation problem [44], supply the overpower demand, and absorb the regenerative braking power. The FC functions to supply the power to both the DC bus capacitor $C_{\text {bus }}$ and the battery to be charged when its SOC is low. The control of the whole system is based on the SOC of the battery [6]:

(i) when SOC is lower than SOC reference, FC is necessary to charge the battery through the bidirectional DC/DC converter;

(ii) when SOC is higher than its reference value, then the battery charging current reference is set to zero and the FC current reference is reduced to zero. For transient conditions, the battery supplies all load variations.

The main objective of the control is to regulate DC bus voltage $v_{\text {bus }}$ and prevent the FC suffering from fast current demand. Two SOSM controllers have been proposed for the unidirectional boost FC converter and the bidirectional battery converter. The bidirectional property allows the management of charge/discharge cycles of the battery tank.

3.1. Adaptive-Gain Supertwisting Sliding Mode Control. Consider a single-input uncertain nonlinear system

$$
\dot{x}=f(x)+g(x) u, \quad y=s(x, t),
$$

where $x \in X \subset \mathbb{R}^{n}$ is a state vector, $u \in U \subset \mathbb{R}$ is a bounded control input, and $f(x), g(x)$ are sufficiently smooth uncertain functions. The control objective is to force the sliding variable $s(x, t)$ and its time derivative and $\dot{s}(x, t)$ to zero in finite time, that is, $s(x, t)=\dot{s}(x, t)=0$.

Assumption 2(See [31]). The relative degree of the system (15) equals one with respect to $u$ and the internal dynamics are stable.
Therefore, under the Assumption 2, the first time derivative of $s(x, t)$ can be presented in the following form:

$$
\begin{aligned}
\dot{s} & =\underbrace{\frac{\partial s}{\partial t}+\frac{\partial s}{\partial x} f(x)}_{\varphi(x, t)}+\underbrace{\frac{\partial s}{\partial x} g(x) u,}_{\gamma(x, t)} \\
& =\varphi(x, t)+\gamma(x, t) u .
\end{aligned}
$$

Assumption 3. The time derivative of the function $\varphi(x, t)$ is bounded, $|\dot{\varphi}(x, t)| \leq \delta$ with an unknown value $\delta, \forall x \in X$.

Assumption 4. There exist positive but unknown constants $\gamma_{m}$ and $\gamma_{M}$, such that $\forall x \in X, 0<b_{m}<|\gamma(x, t)|<b_{M}$ and $|\dot{\gamma}(x, t)| \leq B$.

The following ASTW algorithm is considered [31]

$$
\begin{aligned}
& u=-\alpha|s|^{1 / 2} \operatorname{sign}(s)+v, \\
& \dot{v}=-\beta \operatorname{sign}(s),
\end{aligned}
$$

where $\alpha=\alpha(s, t)$ and $\beta=\beta(s, t)$ are the adaptive gains to be determined.

The system (16) can be rewritten as

$$
\begin{aligned}
& \dot{s}=-\alpha \gamma(x, t)|s|^{1 / 2} \operatorname{sign}(s)+\omega, \\
& \dot{\omega}=-\beta \gamma(x, t) \operatorname{sign}(s)+\dot{\varphi}(x, t)+\dot{\gamma}(x, t) \nu,
\end{aligned}
$$

where $\omega(0)=0$.

Given that $\beta \leq \beta^{*}>0$ [31] and Assumption 4, it follows that

$$
\begin{aligned}
|\dot{\varphi}(x, t)+\dot{\gamma}(x, t) \nu| & \leq \delta+B \int_{0}^{t} \beta d \tau, \\
& \leq \delta+B \beta^{*} t=\delta_{1},
\end{aligned}
$$

for some unknown positive constant $\delta_{1}$.

The control gains $\alpha$ and $\beta$ are adapted dynamically [31]

$$
\begin{aligned}
& \dot{\alpha}= \begin{cases}\omega_{1} \sqrt{\frac{\gamma_{1}}{2}} \operatorname{sign}(|s|-\mu), & \text { if } \alpha>\alpha_{m}, \\
\eta_{1}, & \text { if } \alpha \leq \alpha_{m},\end{cases} \\
& \beta=\varepsilon_{1} \alpha,
\end{aligned}
$$

where $\omega_{1}, \gamma_{1}, \mu, \eta_{1}, \varepsilon_{1}$, and $\alpha_{m}$ are arbitrary positive constants.

Remark 5. The practical sliding mode is established in finite time $t_{F}$, that is, $|s| \leq \mu_{1},|\dot{s}| \leq \mu_{2}$. At the beginning, $|s(0)|>\mu$ and $\alpha(0)>\alpha_{m}$, and the adaptive gains $\alpha$ and $\beta$ dynamically increase in order to stabilize the system. Once the practical sliding mode is achieved, the gains start to decrease.

3.2. FC Reference Power Calculation. In this study, state based control algorithm proposed in the work [45] is used to calculate the FC reference power $P_{\mathrm{fc}}^{*}$. The FC reference power is determined based on the load power and battery SOC. Three levels for the SOC range are considered: high (SOC > $90 \%)$, normal $(60 \% \leq$ SOC $\leq 85 \%)$, and low $($ SOC $<30 \%)$. Eight states derived from the works of [45-47] are given as follows. 

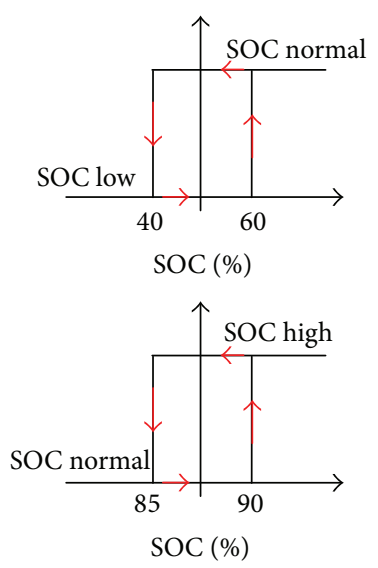

FIGURE 3: State based control hysteresis.

Case 1. SOC is high and $P_{\text {load }}<P_{\mathrm{fc}_{\min }}$. In this case, the FC operates at its minimum power $P_{\mathrm{fc}}^{*}=P_{\mathrm{fc}_{\min }}$, only supplies auxiliary components.

Case 2. SOC is high and $P_{\mathrm{fc}_{\min }} \leq P_{\text {load }} \leq P_{\mathrm{fc}_{\max }}$. In this case, the FC operates with a load following strategy $P_{\mathrm{fc}}^{*}=P_{\text {load }}$ and the battery will supply the fast load demand when necessary.

Case 3. SOC is high and $P_{\text {load }} \geq P_{\mathrm{fc}_{\text {min }}}$. In this case, the FC is demanded to generate its maximum power $P_{\mathrm{fc}}^{*}=P_{\mathrm{fc}_{\max }}$ and the battery will provide additional power to assist the FC.

Case 4. SOC is normal and $P_{\text {load }}<P_{\mathrm{fc}_{\mathrm{opt}}}$. In this case, the FC operates at its optimum power $P_{\mathrm{fc}}^{*}=P_{\mathrm{fc}_{\mathrm{opt}}}$.

Case 5. SOC is normal and $P_{\mathrm{fc}_{\mathrm{opt}}} \leq P_{\text {load }} \leq P_{\mathrm{fc}_{\mathrm{max}}}$. In this case, the FC operates with a load following strategy, which works the same as Case 2 .

Case 6. SOC is normal and $P_{\text {load }} \geq P_{\mathrm{fc}_{\max }}$. In this case, the FC is demanded to generate its maximum power $P_{\mathrm{fc}}^{*}=P_{\mathrm{fc}_{\max }}$; it works the same as Case 3.

Case 7. SOC is low and $P_{\text {load }}<P_{\mathrm{fc}_{\text {max }}}$. In this case, the FC must generate the load power plus the battery charging power, $P_{\mathrm{fc}}^{*}=$ $P_{\mathrm{fc}_{\max }}+P_{\text {batt }_{\text {char }}}$.

Case 8. SOC is low and $P_{\text {load }} \geq P_{\mathrm{fc}_{\max }}$. In this case, the FC is required to generate the maximum power, $P_{\mathrm{fc}}^{*}=P_{\mathrm{fc}_{\max }}$.

The hysteresis control of the battery SOC is shown in Figure 3.

3.3. Control of FC Converter. The detailed FC current regulation loop is portrayed in Figure 4. From the FC reference power generated by the states control algorithm and the FC voltage, the FC reference current is determined which is limited to a range $\left[i_{\mathrm{fc}_{\min }}, i_{\mathrm{fc}_{\max }}\right]$. In the case of within the interval, the control of $\mathrm{FC}$ boost converter ensures current regulation (with respect to its reference value). In the case of outside the interval, the FC current will be saturated and the surge current is then provided or absorbed by the battery. Moreover, the FC dynamic limitation is also considered using a low pass filter, such that fast current demand is avoided. The error between the FC current and its reference is used in a SOSM controller in order to determine the duty cycle of the FC unidirectional converter [48].

The sliding manifold of the FC current control loop is defined as

$$
s_{1}=i_{\mathrm{fc}, \mathrm{ref}}-i_{\mathrm{fc}} \cdot
$$

In view of (7), the first time derivative of $s_{1}$ is calculated as follows:

$$
\dot{s}_{1}=\dot{i}_{\mathrm{fc}, \text { ref }}-\frac{V_{\mathrm{fc}}-r_{\mathrm{fc}} i_{\mathrm{fc}}-u_{\mathrm{fc}} V_{\mathrm{bus}}}{L_{\mathrm{fc}}} .
$$

According to the adaptive SOSM algorithm [31], the FC current controller can be designed as follows:

$$
u_{\mathrm{fc}}=\frac{V_{\mathrm{fc}}-r_{\mathrm{fc}} i_{\mathrm{fc}}-L_{\mathrm{fc}} v_{1}\left(s_{1}\right)}{V_{\mathrm{bus}}},
$$

where $v_{1}\left(s_{1}\right)$ takes the same structure as (17):

$$
\begin{aligned}
& v_{1}\left(s_{1}\right)=v_{11}\left(s_{1}\right)+v_{12}\left(s_{1}\right), \\
& \dot{v}_{11}\left(s_{1}\right)=-\beta_{1} \operatorname{sign}\left(s_{1}\right), \\
& v_{12}\left(s_{1}\right)=-\alpha_{1}\left|s_{1}\right|^{1 / 2} \operatorname{sign}\left(s_{1}\right),
\end{aligned}
$$

and the adaptive gains $\alpha_{1}$ and $\beta_{1}$ are designed according to $(20)$. In order to ensure the fast convergence of $s_{1}$, the parameters have been tuned as follows: $\omega_{1}=150, \gamma_{1}=2.5$, $\mu_{1}=0.1, \eta_{1}=25, \alpha_{1 m}=0.01$, and $\varepsilon_{1}=2$.

3.4. Battery Control. A cascade control structure is proposed, which consists of the outer control loop (DC bus energy control) and the inner control loop (battery current control), as shown in Figure 5. The DC bus energy regulation law generates the battery reference power $P_{\text {batt }}^{*}$. This reference value is then divided by the measured battery voltage $V_{\text {batt }}$ in order to obtain the battery reference current $i_{\text {batt }}^{*}$, which is limited by its maximum and minimum current $\left(i_{\text {batt,max }}\right.$ and $\left.i_{\text {batt, min }}\right)$.

The error between the battery current and its reference is used in another SOSM controller in order to determine the duty cycle of the battery bidirectional converter. On the one hand, the battery is in the discharge mode when the system demands power from the battery, and the duty cycle of the battery converter increases in order to supply power to maintain the DC bus voltage. On the other hand, the battery is in the charge mode when there is excess power in the system, and the duty cycle of the battery converter decreases and, thus, the battery voltage increases. Therefore, the battery converter is controlled for DC bus energy regulation and is switching between the charge and discharge modes [46].

3.4.1. External Control Loop. For the DC bus energy regulation, a SOSMC is employed, with the error between the bus 


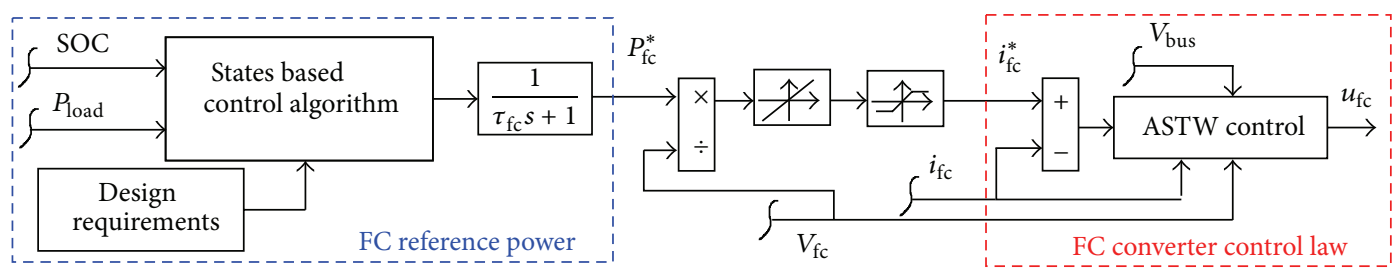

FIgURE 4: Control law of FC current.

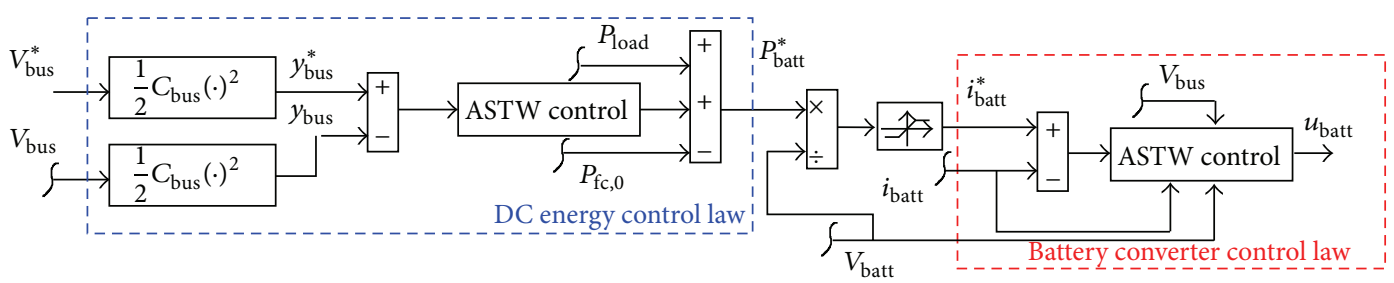

FIGURE 5: Control law of battery current.
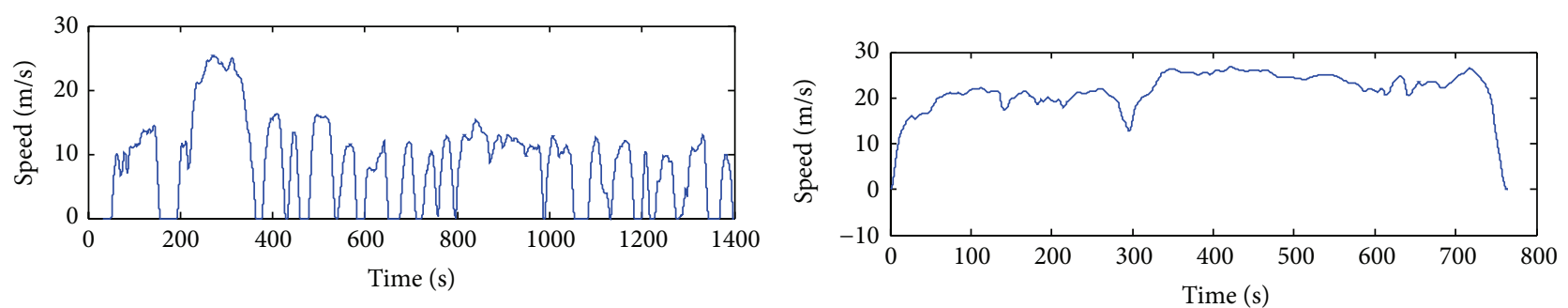

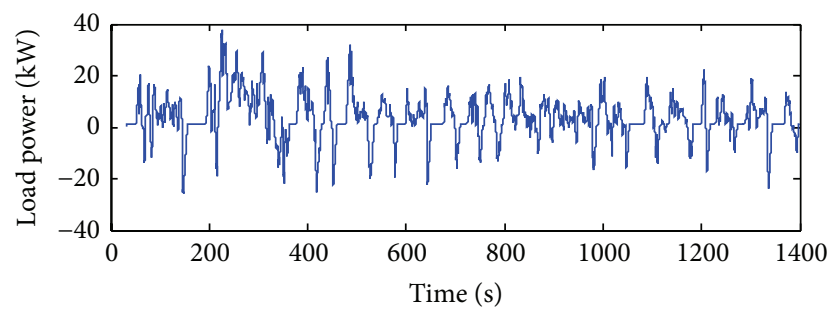

(a) UDDS

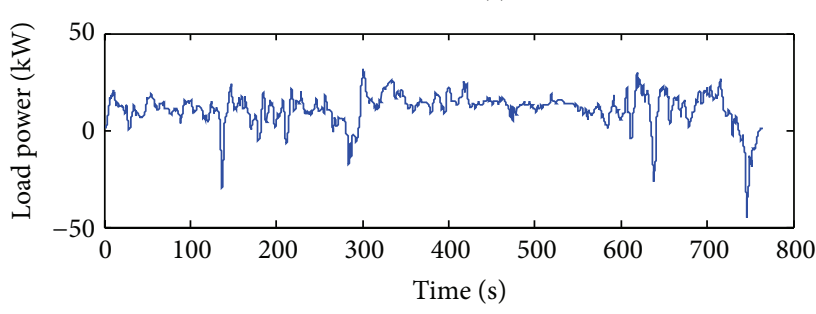

(b) HWFET

FIgURE 6: Standard driving cycles (UDDS and HWFET).

energy and its reference as input. The sliding manifold of the outer loop is defined as

$$
s_{2}=y_{\text {bus }}^{*}-y_{\text {bus }}
$$

where $y_{\text {bus }}^{*}=0.5 C_{\text {bus }}\left(V_{\text {bus }}^{*}\right)^{2}$ and $y_{\text {bus }}=0.5 C_{\text {bus }} V_{\text {bus }}^{2}$.

In view of (12), the first time derivative of $s_{2}$ is calculated as follows:

$$
\dot{s}_{2}=-P_{\mathrm{fc}, 0}-P_{\text {batt }}+r_{\text {batt }} i_{\text {batt }}^{2}+P_{\text {load }} .
$$

Then, the battery power reference is obtained as

$$
P_{\text {batt }}^{*}=v_{2}\left(s_{2}\right)-P_{\mathrm{fc}, 0}+r_{\text {batt }} i_{\text {batt }}^{2}+P_{\text {load }},
$$

where $v_{2}\left(s_{2}\right)$ is the adaptive SOSM controller with the same structure of (20) and (24).

The battery reference current is obtained as follows:

$$
i_{\text {batt }}^{*}=\frac{P_{\text {batt }}^{*}}{V_{\text {batt }}} .
$$

3.4.2. Inner Control Loop. The inner loop contains a SOSM current controller which generates the duty cycle of the battery bidirectional converter. The sliding manifold of the inner loop is defined as

$$
s_{3}=i_{\text {batt }}^{*}-i_{\text {batt }} .
$$

In view of (11), the first time derivative of $s_{3}$ is calculated as follows:

$$
\dot{s}_{3}=\dot{i}_{\text {batt }}^{*}-\frac{V_{\text {batt }}-r_{\text {batt }} i_{\text {batt }}-u_{\text {batt }} V_{\text {bus }}}{L_{\text {batt }}} .
$$

The battery current controller $u_{\text {batt }}$ is designed using the adaptive SOSM algorithm

$$
u_{\text {batt }}=\frac{V_{\text {batt }}-r_{\text {batt }} i_{\text {batt }}-L_{\text {batt }} v_{3}\left(s_{3}\right)}{V_{\text {bus }}},
$$

where $v_{3}\left(s_{3}\right)$ is the adaptive SOSM controller with the same structure of (20) and (24). 

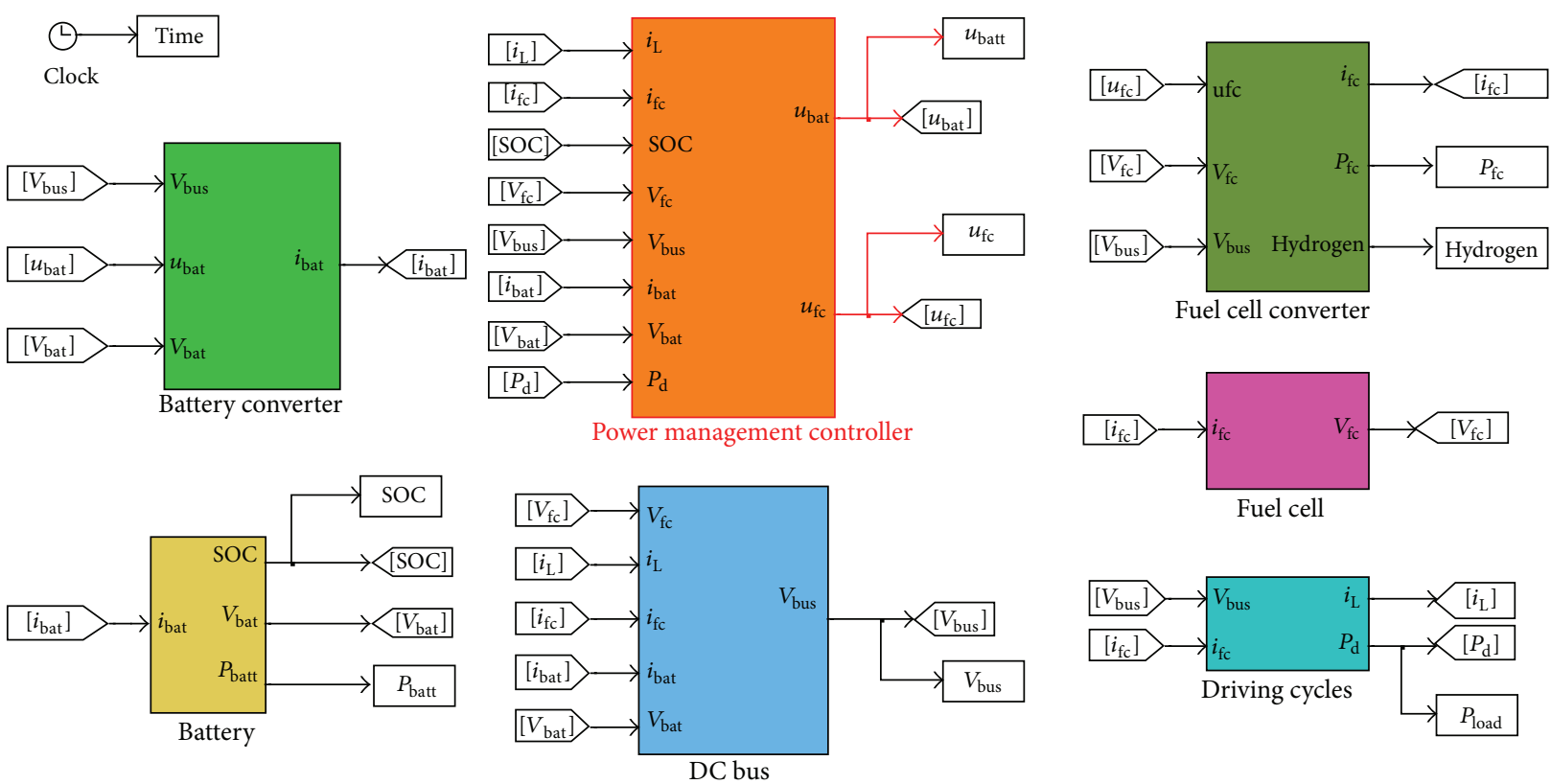

Fuel cell

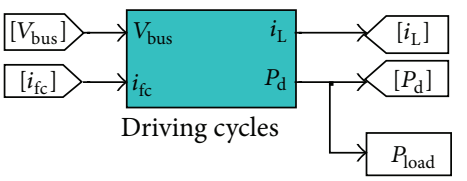

FIGURE 7: Hybrid system configuration.

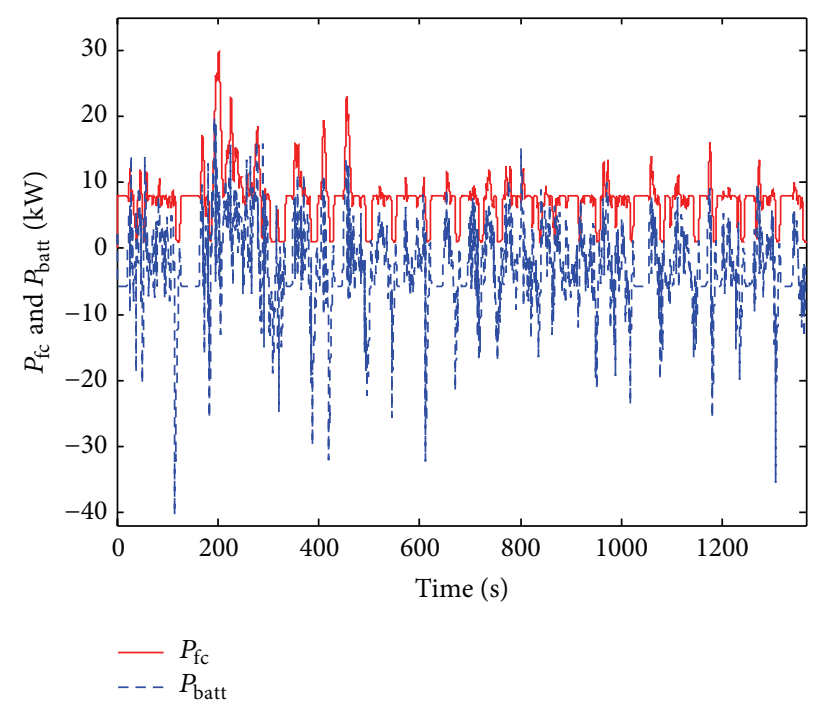

(a) UDDS

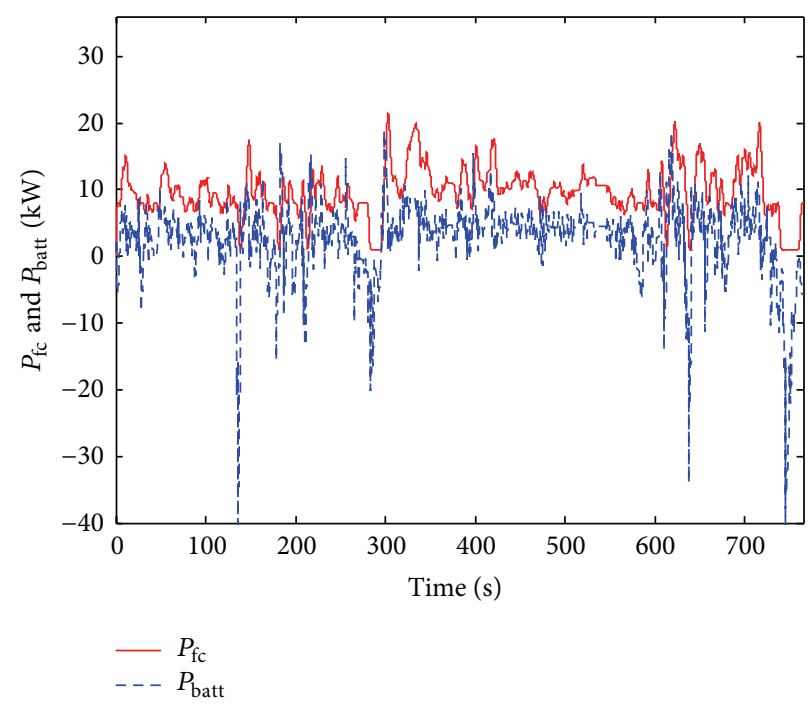

(b) HWFET

FIGURE 8: FC and battery powers under UDDS and HWFET driving cycles.

Remark 6. Due to the cascade control structure and the constant switching frequency $\omega_{S}$ of the power electronic, the cutoff frequency of the inner loop $\omega_{I}$ is ten times higher than that of the outer loop $\omega_{\mathrm{O}}$ and less than $\omega_{S}$, that is, $\omega_{\mathrm{O}} \ll \omega_{I} \ll$ $\omega_{S}$. In order to have an effective cascade control system, it is essential that the inner loop responds much faster than the outer loop.

\section{Simulation Results and Discussion}

The proposed hybrid system and control strategies have been implemented in MATLAB/Simulink and tested for the standard drive cycles, that is, the Urban Dynamometer Driving Schedule (UDDS) and Highway Fuel Economy Driving Schedule (HWFET). The UDDS and HWFET were used to represent typical driving conditions of light duty vehicles in the city and highway driving conditions, respectively. In this paper, the driving cycle implemented in the FC-Battery hybrid system is obtained from the simulation package Advanced Vehicle Vehicle Simulator (ADVISOR) [49]. Specific characteristics of the UDDS are shown in Table 3 . The speed and mechanical power required by the electrical vehicle is shown in Figure 6. The implementation of the proposed EMS in the FC-battery hybrid system is shown in Figure 7. 


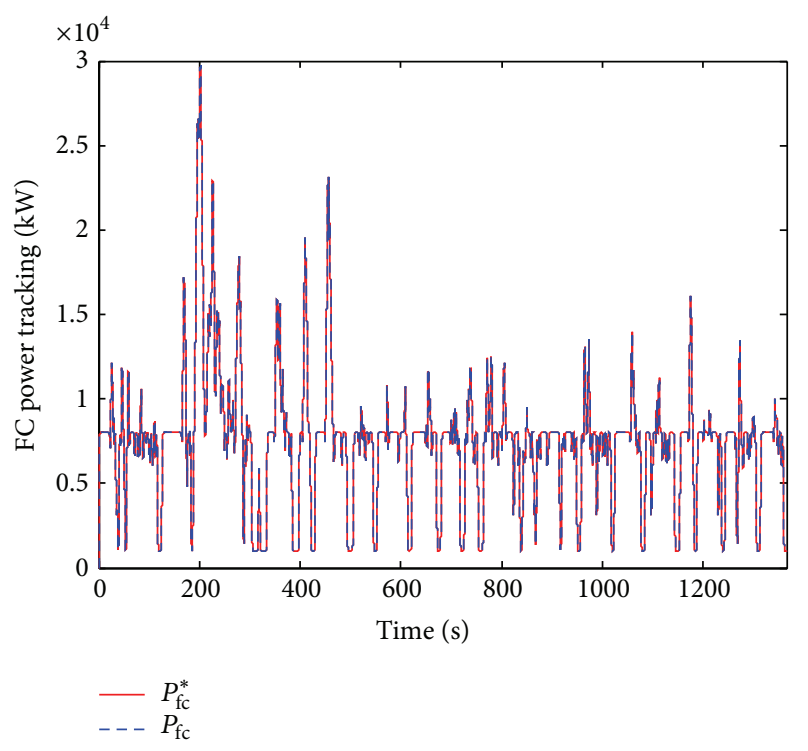

(a) UDDS

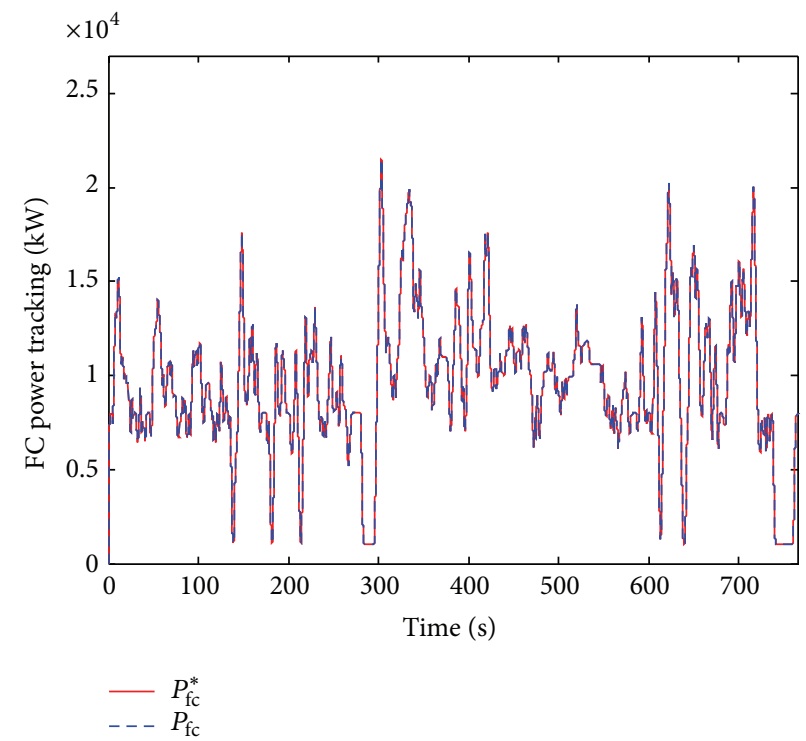

(c) HWFET

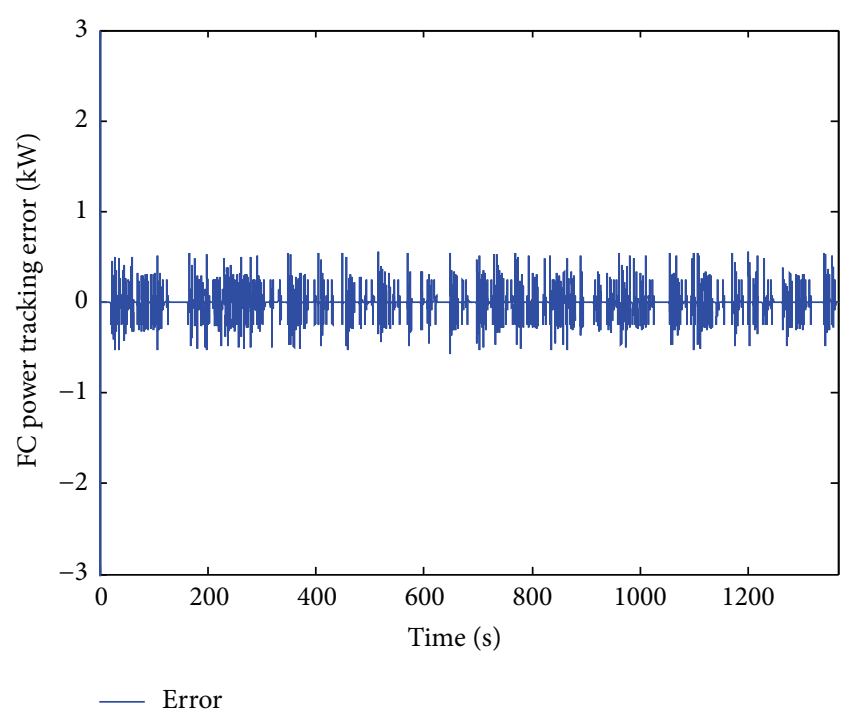

(b) UDDS

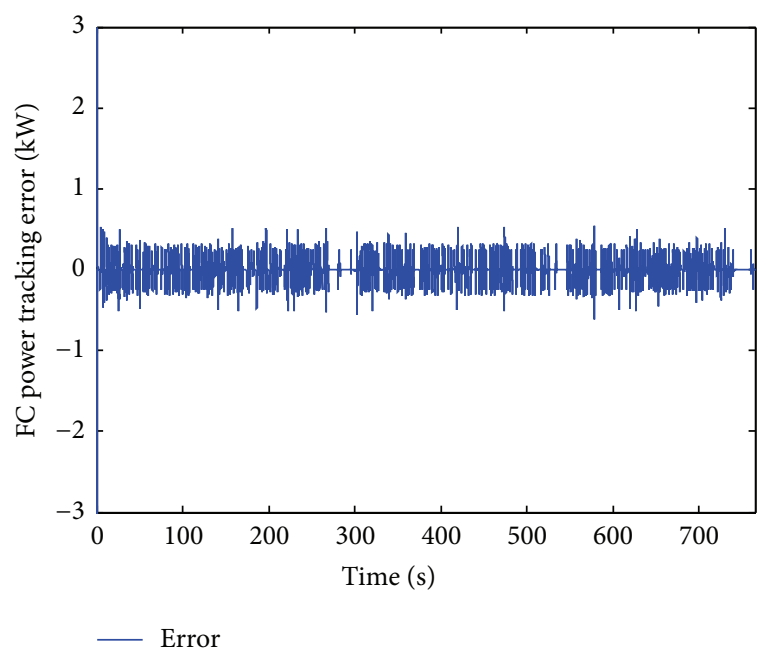

(d) HWFET

FIGURE 9: FC power tracking and its error under UDDS and HWFET driving cycles.

The multirate simulation of the proposed FC-battery hybrid system has been carried out. Multirate approach realizes the achievement of realistic simulation results by taking into account some implementation issues:

(1) the control evaluation rate $f_{2}$ is less than the simulation rate $f_{1}$ (i.e., the integration was carried out according to the Euler method);

(2) the power elements switch rate $f_{3}$ is less than the control evaluation rate $f_{2}$ due to switching loss.

The parameters of the PEMFC system and multirate approach used in this study are shown in Tables 4 and 5. Parameters associated with the FC converter control and battery converter control are given in Table 2.
TABLE 3: Driving cycle specific characteristics [50].

\begin{tabular}{lcc}
\hline Driving cycle & UDDS & HWFET \\
Duration & $1369 \mathrm{~s}$ & $765 \mathrm{~s}$ \\
Distance & $12.07 \mathrm{~km}$ & $16.45 \mathrm{~km}$ \\
Maximum speed & $56.7 \mathrm{mph}$ & $59.90 \mathrm{mph}$ \\
Average speed & $19.58 \mathrm{mph}$ & $48.28 \mathrm{mph}$ \\
Average accelerate & $0.50 \mathrm{~m} / \mathrm{s}^{2}$ & $0.19 \mathrm{~m} / \mathrm{s}^{2}$ \\
Average decelerate & $-0.58 \mathrm{~m} / \mathrm{s}^{2}$ & $-0.22 \mathrm{~m} / \mathrm{s}^{2}$ \\
\hline
\end{tabular}

The tests are performed under the same initial conditions: the initial battery SOC $=0.5$, the initial FC voltage $V_{\mathrm{fc}}=$ $350 \mathrm{~V}$, and the initial FC temperature $T_{\mathrm{fc}}=353.15 \mathrm{~K}$. The 


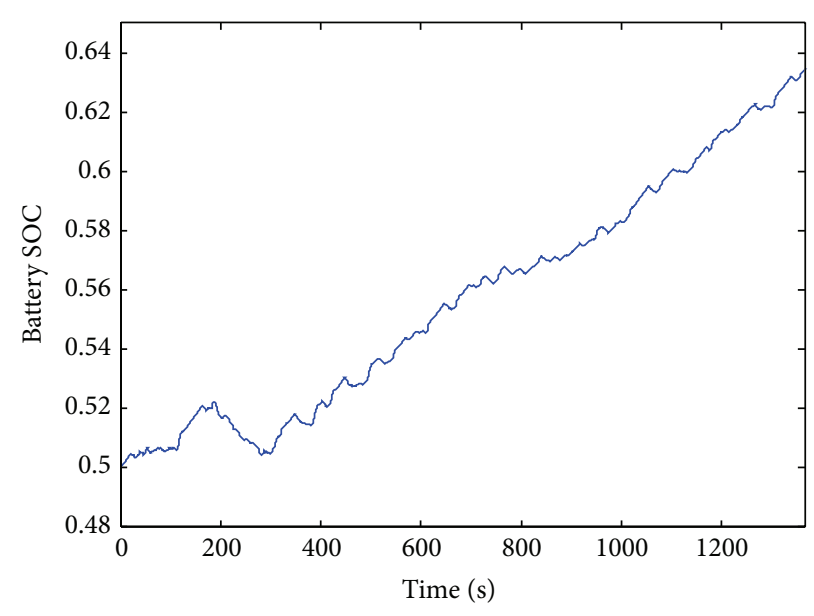

- SOC

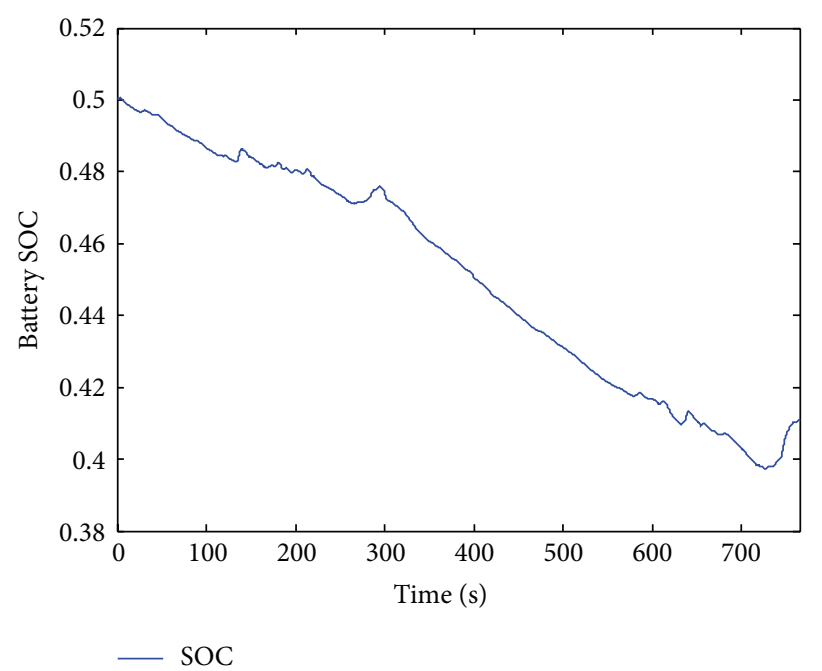

(b) HWFET

(a) UDDS

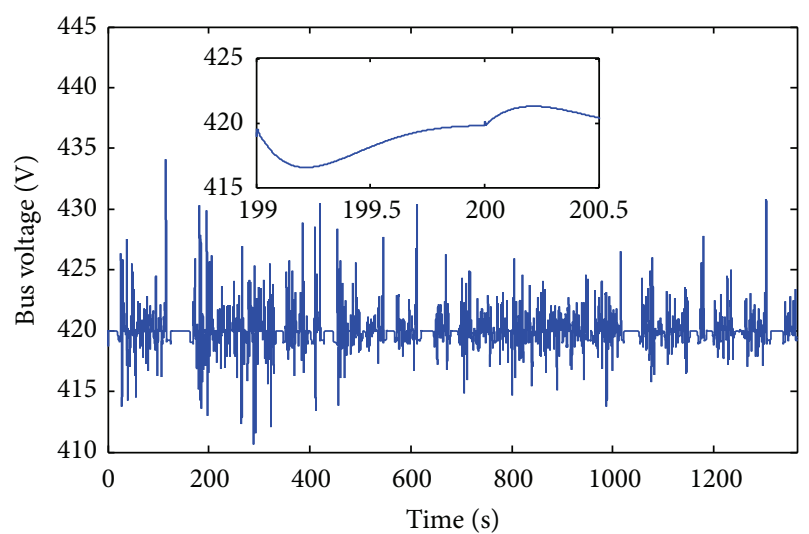

(b) PI (UDDS)

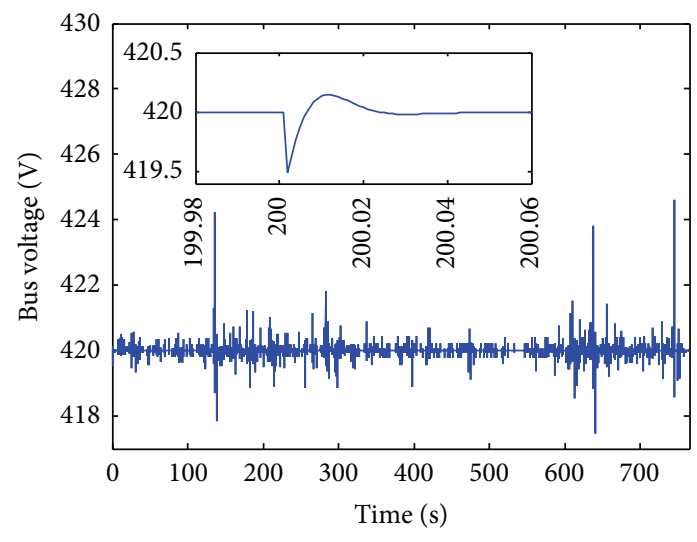

- V bus

(c) ASTW (HWFET)

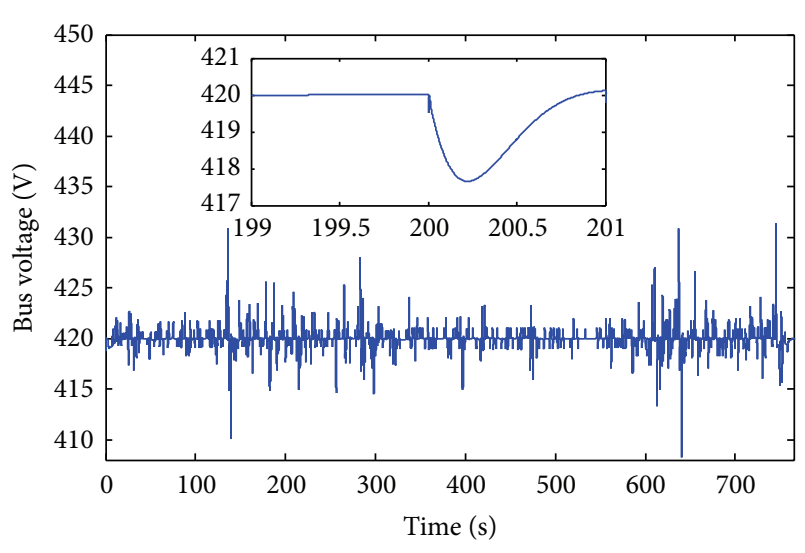

$-V_{\text {bus }}$

FIGURE 11: DC bus voltage performance under UDDS and HWFET driving cycles. 


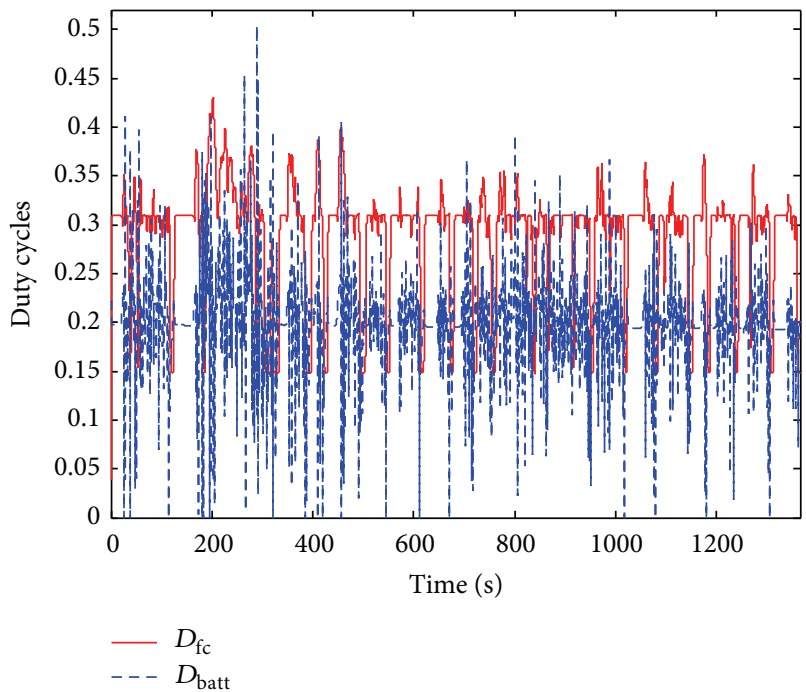

(a) UDDS

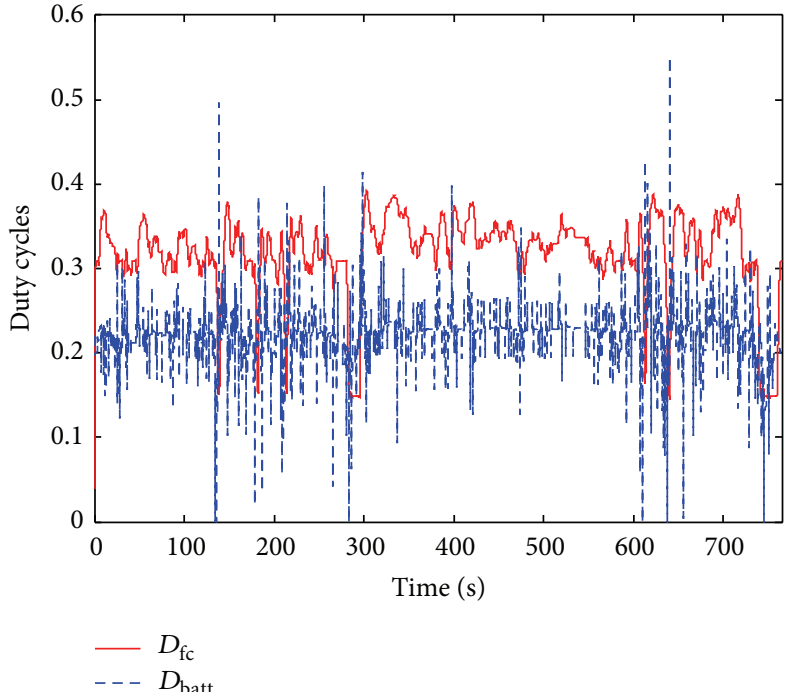

(b) HWFET

FIGURE 12: Duty cycles of the FC and battery converters under UDDS and HWFET driving cycles.

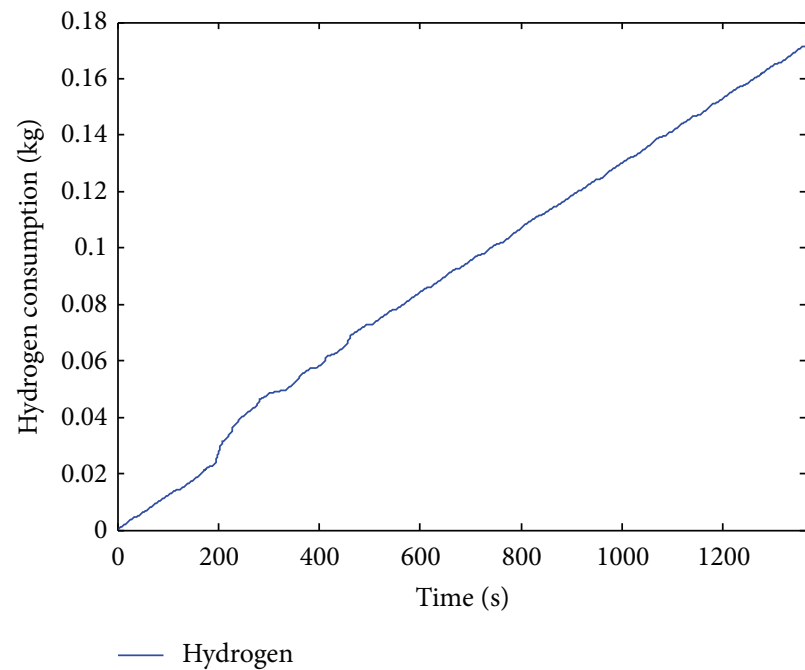

(a) UDD

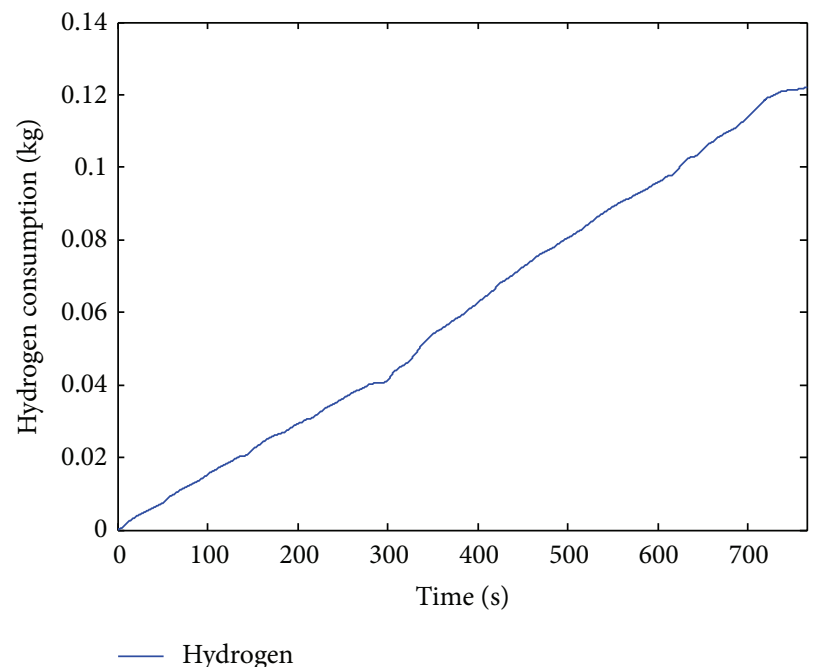

(b) HWFET

FIGURE 13: Hydrogen consumption under UDDS and HWFET driving cycles.

simulation results under UDDS and HWFET driving cycles are shown Figures 8-13.

It is shown from Figure 8 that both the fuel cell and battery output powers are in their allowable operational ranges. In addition, the FC power works often at its optimal power which increases the the efficiency. The rate of change of the FC power is significantly alleviated using the state based control. Figure 9 presents the performance of the proposed ASTW controller for regulating the FC power to its reference value. Figures $9(\mathrm{~b})$ and $9(\mathrm{~d})$ prove the effectiveness of the controller. Figure 10 shows that the battery SOC are successfully sustained between $\mathrm{SOC}_{\min }=0.3$ and $\mathrm{SOC}_{\max }=$ 0.9 under both driving cycles.
The DC bus voltage performance is compared with a welltuned linear Proportional-Integral (PI) controller, as shown in Figure 11. The proposed ASTW controller stabilized the DC bus voltage at the reference value $V_{\text {bus }}^{*}=420 \mathrm{~V}$ which acts in the outer control loop, while PI control results in higher fluctuation around the desired value and higher voltage overshoot compared with the adaptive ASTW control. Faster convergence can also be observed from the enlarged view. Some overshoots of the DC bus voltage can be observed from Figure 11; this is because the power demands change rapidly at the DC bus during the driving process. Figure 12 gives the duty cycles of the FC unidirectional converter and battery bidirectional converter, which are generated from the 
TABLE 4: PEMFC system parameters.

\begin{tabular}{lcc}
\hline Symbol & Parameter & Value \\
\hline$n$ & Number of cells in stack & 381 \\
$R$ & Universal gas constant & $8.314 \mathrm{~J} /(\mathrm{mol} \mathrm{K})$ \\
$T_{\mathrm{fc}}$ & Temperature of the fuel cell & $353.15 \mathrm{~K}$ \\
$F$ & Faraday constant & $96485 \mathrm{C} / \mathrm{mol}$ \\
$p_{\mathrm{atm}}$ & Atmospheric pressure & $1.01325 \times 10^{5} \mathrm{~Pa}$ \\
$T_{\mathrm{atm}}$ & Atmospheric temperature & $298.15 \mathrm{~K}$ \\
$V_{\mathrm{ca}}$ & Cathode volume & $0.01 \mathrm{~m}^{3}$ \\
$V_{\mathrm{an}}$ & Anode volume & $0.005 \mathrm{~m}^{3}$ \\
$x_{\mathrm{O}_{2}, \text { atm }}$ & Oxygen mass fraction & 0.23 \\
$M_{a}$ & Air molar mass & $28.9644 \times 10^{-3} \mathrm{~kg} / \mathrm{mol}$ \\
$M_{\mathrm{O}_{2}}$ & Oxygen molar mass & $32 \times 10^{-3} \mathrm{~kg} / \mathrm{mol}$ \\
$M_{\mathrm{N}_{2}}$ & Nitrogen molar mass & $28 \times 10^{-3} \mathrm{~kg} / \mathrm{mol}$ \\
$\gamma$ & Ratio of specific heats of air & 1.4 \\
$C_{p}$ & Specific heat capacity of air & $1004 \mathrm{~J} /(\mathrm{kg} \mathrm{K})$ \\
$\eta_{\mathrm{cp}}$ & Compressor efficiency & $80 \%$ \\
$\eta_{\mathrm{cm}}$ & Motor mechanical efficiency & $98 \%$ \\
\hline
\end{tabular}

TABle 5: Parameters for the multirate simulation.

\begin{tabular}{lcc}
\hline Symbol & Parameter & Value \\
\hline$f_{1}$ & Simulation rate & $10 \mathrm{kHz}$ \\
$f_{2}$ & Sampling rate & $2 \mathrm{kHz}$ \\
$f_{3}$ & Chopping frequency & $1 \mathrm{kHz}$ \\
\hline
\end{tabular}

FC current control loop and the battery current control loop, respectively. Both of the current control loop are based on the proposed ASTW algorithm, which act in the inner loop. Figure 13 shows the hydrogen consumption under UDDS and HWFET driving cycles.

\section{Conclusions}

This paper investigated the power management control for a FC hybrid system using a Li-ion battery stack as a secondary storage element. A hysteresis controller is proposed to determine the power reference for the fuel cell stack. The adaptive STW control is employed for the fuel cell converter to track the given power command while satisfying the power limitations. A cascade control structure is also designed for the battery converter, where the battery current control acts as the inner loop and the DC bus regulation acts as the outer loop which aims to stabilize the DC bus voltage. Both of the control loops are based on the adaptive STW algorithm. Finally, multirate simulations are carried out in the MatlabSimulink environment over two driving cycles, UDDS and HWFET. The simulations results have shown that the proposed approach is effective and feasible.

\section{Conflict of Interests}

The authors declare that there is no conflict of interests regarding the publication of this paper.

\section{References}

[1] A. Al-Durra, S. Yurkovich, and Y. Guezennec, "Study of nonlinear control schemes for an automotive traction PEM fuel cell system," International Journal of Hydrogen Energy, vol. 35, no. 20, pp. 11291-11307, 2010.

[2] D. Feroldi, M. Serra, and J. Riera, "Design and analysis of fuelcell hybrid systems oriented to automotive applications," IEEE Transactions on Vehicular Technology, vol. 58, no. 9, pp. 47204729, 2009.

[3] T. Raminosoa, B. Blunier, D. Fodorean, and A. Miraoui, "Design and optimization of a switched reluctance motor driving a compressor for a PEM fuel-cell system for automotive applications," IEEE Transactions on Industrial Electronics, vol. 57, no. 9, pp. 2988-2997, 2010.

[4] P. Thounthong, S. Raël, and B. Davat, "Energy management of fuel cell/battery/supercapacitor hybrid power source for vehicle applications," Journal of Power Sources, vol. 193, no. 1, pp. 376385, 2009.

[5] T. Kojima, T. Ishizu, T. Horiba, and M. Yoshikawa, "Development of lithium-ion battery for fuel cell hybrid electric vehicle application," Journal of Power Sources, vol. 189, no. 1, pp. 859863, 2009.

[6] P. Thounthong, S. Raël, and B. Davat, "Control algorithm of fuel cell and batteries for distributed generation system," IEEE Transactions on Energy Conversion, vol. 23, no. 1, pp. 148-155, 2008.

[7] J. E. Dawes, N. S. Hanspal, O. A. Family, and A. Turan, “Threedimensional CFD modelling of PEM fuel cells: an investigation into the effects of water flooding," Chemical Engineering Science, vol. 64, no. 12, pp. 2781-2794, 2009.

[8] R. J. Talj, D. Hissel, R. Ortega, M. Becherif, and M. Hilairet, "Experimental validation of a PEM fuel-cell reduced-order model and a moto-compressor higher order sliding-mode control," IEEE Transactions on Industrial Electronics, vol. 57, no. 6, pp. 1906-1913, 2010.

[9] S. V. Puranik, A. Keyhani, and F. Khorrami, "Neural network modeling of proton exchange membrane fuel cell," IEEE Transactions on Energy Conversion, vol. 25, no. 2, pp. 474-483, 2010.

[10] S. Yin, G. Wang, and X. Yang, "Robust PLS approach for KPIrelated prediction and diagnosis against outliers and missing data," International Journal of Systems Science, vol. 45, no. 7, pp. 1375-1382, 2014.

[11] S. Yin, G. Wang, and H. R. Karimi, "Data-driven design of robust fault detection system for wind turbines," Mechatronics, vol. 24, no. 4, pp. 298-306, 2014.

[12] S. Yin, X. Yang, and H. R. Karimi, "Data-driven adaptive observer for fault diagnosis," Mathematical Problems in Engineering, vol. 2012, Article ID 832836, 21 pages, 2012.

[13] S. Yin, X. Li, H. Gao, and O. Kaynak, "Data-based techniques focused on modern industry: an overview," IEEE Transactions on Industrial Electronics, 2014.

[14] C. Lin, H. Peng, J. W. Grizzle, and J. Kang, "Power management strategy for a parallel hybrid electric truck," IEEE Transactions on Control Systems Technology, vol. 11, no. 6, pp. 839-849, 2003.

[15] B. Geng, J. K. Mills, and D. Sun, "Energy management control of microturbine-powered plug-in hybrid electric vehicles using the telemetry equivalent consumption minimization strategy," IEEE Transactions on Vehicular Technology, vol. 60, no. 9, pp. 4238-4248, 2011. 
[16] B. Geng, J. K. Mills, and D. Sun, “Two-stage energy management control of fuel cell plug-in hybrid electric vehicles considering fuel cell longevity," IEEE Transactions on Vehicular Technology, vol. 61, no. 2, pp. 498-508, 2012.

[17] M. C. Kisacikoglu, M. Uzunoglu, and M. S. Alam, "Load sharing using fuzzy logic control in a fuel cell/ultracapacitor hybrid vehicle," International Journal of Hydrogen Energy, vol. 34, no. 3, pp. 1497-1507, 2009.

[18] D. Gao, Z. Jin, and Q. Lu, "Energy management strategy based on fuzzy logic for a fuel cell hybrid bus," Journal of Power Sources, vol. 185, no. 1, pp. 311-317, 2008.

[19] Z. Amjadi and S. S. Williamson, "Power-electronics-based solutions for plug-in hybrid electric vehicle energy storage and management systems," IEEE Transactions on Industrial Electronics, vol. 57, no. 2, pp. 608-616, 2010.

[20] J. Liu, S. Laghrouche, and M. Wack, "Adaptive-gain secondorder sliding mode observer design for switching power converters," Control Engineering Practice, vol. 30, pp. 124-131, 2014.

[21] J. Liu, S. Laghrouche, and M. Wack, “Observer-based higher order sliding mode control of power factor in three-phase AC/DC converter for hybrid electric vehicle applications," International Journal of Control, vol. 87, no. 6, pp. 1117-1130, 2014.

[22] L. Wang, H. Zhang, and X. Liu, "Sliding mode variable structure I/O feedback linearization design for the speed control of PMSM with load torque observer," International Journal of Innovative Computing, Information and Control, vol. 9, no. 8, pp. 3485-3496, 2013.

[23] B. Xiao, Q. Hu, and G. Ma, "Adaptive sliding mode backstepping control for attitude tracking of flexible spacecraft under input saturation and singularity," Proceedings of the Institution of Mechanical Engineers G: Journal of Aerospace Engineering, vol. 224, no. 2, pp. 199-214, 2010.

[24] B. Xiao, Q. Hu, and Y. Zhang, "Adaptive sliding mode fault tolerant attitude tracking control for flexible spacecraft under actuator saturation," IEEE Transactions on Control Systems Technology, vol. 20, no. 6, pp. 1605-1612, 2012.

[25] L. Wu, W. X. Zheng, and H. Gao, "Dissipativity-based sliding mode control of switched stochastic systems," IEEE Transactions on Automatic Control, vol. 58, no. 3, pp. 785-791, 2013.

[26] L. Wu, X. Su, and P. Shi, "Sliding mode control with bounded $L_{2}$ gain performance of Markovian jump singular time-delay systems," Automatica, vol. 48, no. 8, pp. 1929-1933, 2012.

[27] L. Wu, P. Shi, and H. Gao, "State estimation and slidingmode control of Markovian jump singular systems," IEEE Transactions on Automatic Control, vol. 55, no. 5, pp. 1213-1219, 2010.

[28] M. R. Soltanpour, B. Zolfaghari, M. Soltani, and M. H. Khooban, "Fuzzy sliding mode control design for a class of nonlinear systems with structured and unstructured uncertainties," International Journal of Innovative Computing, Information and Control, vol. 9, no. 7, pp. 2713-2726, 2013.

[29] B. Wang, P. Shi, and H. R. Karimi, "Fuzzy sliding mode control design for a class of disturbed systems," Journal of the Franklin Institute, vol. 351, no. 7, pp. 3593-3609, 2014.

[30] G. Bartolini, A. Ferrara, and E. a. . Usai, "On multi-input chattering-free second-order sliding mode control," IEEE Transactions on Automatic control, vol. 45, no. 9, pp. 1711-1717, 2000.

[31] Y. Shtessel, M. Taleb, and F. Plestan, "A novel adaptive-gain supertwisting sliding mode controller: methodology and application," Automatica, vol. 48, no. 5, pp. 759-769, 2012.
[32] F. Plestan, Y. Shtessel, V. Brégeault, and A. Poznyak, "New methodologies for adaptive sliding mode control," International Journal of Control, vol. 83, no. 9, pp. 1907-1919, 2010.

[33] V. I. Utkin and A. S. Poznyak, "Adaptive sliding mode control with application to super-twist algorithm: equivalent control method," Automatica, vol. 49, no. 1, pp. 39-47, 2013.

[34] J. Pukrushpan, A. Stefanopoulou, and H. Peng, Control of Fuel Cell Power Systems: Principles, Modeling, Analysis and Feedback Design, Springer, New York, NY, USA, 2004.

[35] S. M. Rakhtala, A. R. Noei, R. Ghaderi, and E. Usai, "Design of finite-time high-order sliding mode state observer: a practical insight to PEM fuel cell system," Journal of Process Control, vol. 24, no. 1, pp. 203-224, 2014.

[36] J. Larminie, A. Dicks, and M. S. McDonald, Fuel Cell Systems Explained, vol. 2, Wiley, Chichester, UK, 2003.

[37] K. Kordesch and G. Simader, Fuel Cell and Their Applications, Wiley, 2006.

[38] J. C. Amphlett, R. M. Baumert, R. F. Mann, B. A. Peppley, P. R. Roberge, and T. J. Harris, "Performance modeling of the Ballard Mark IV solid polymer electrolyte fuel cell II. Empirical model development," Journal of the Electrochemical Society, vol. 142, no. 1, pp. 9-15, 1995.

[39] S.-Y. Choe, J.-W. Ahn, J.-G. Lee, and S.-H. Baek, "Dynamic simulator for a PEM fuel cell system with a PWM DC/DC converter," IEEE Transactions on Energy Conversion, vol. 23, no. 2, pp. 669-680, 2008.

[40] A. Vahidi, A. Stefanopoulou, and H. Peng, "Current management in a hybrid fuel cell power system: a model-predictive control approach," IEEE Transactions on Control Systems Technology, vol. 14, no. 6, pp. 1047-1057, 2006.

[41] E. A. Müller, A. G. Stefanopoulou, and L. Guzzella, "Optimal power control of hybrid fuel cell systems for an accelerated system warm-up," IEEE Transactions on Control Systems Technology, vol. 15, no. 2, pp. 290-305, 2007.

[42] P. Thounthong, S. Raël, and B. Davat, "Test of a PEM fuel cell with low voltage static converter," Journal of Power Sources, vol. 153, no. 1, pp. 145-150, 2006.

[43] S. J. Moura, H. K. Fathy, D. S. Callaway, and J. L. Stein, "A stochastic optimal control approach for power management in plug-in hybrid electric vehicles," IEEE Transactions on Control Systems Technology, vol. 19, no. 3, pp. 545-555, 2011.

[44] J. T. Pukrushpan, A. G. Stefanopoulou, and H. Peng, "Control of fuel cell breathing," IEEE Control Systems Magazine, vol. 24, no. 2, pp. 30-46, 2004.

[45] L. M. Fernandez, P. Garcia, C. A. Garcia, J. P. Torreglosa, and F. Jurado, "Comparison of control schemes for a fuel cell hybrid tramway integrating two dc/dc converters," International Journal of Hydrogen Energy, vol. 35, no. 11, pp. 5731-5744, 2010.

[46] P. Garcia, L. M. Fernandez, C. A. Garcia, and F. Jurado, "Energy management system of fuel-cell-battery hybrid tramway," IEEE Transactions on Industrial Electronics, vol. 57, no. 12, pp. 40134023, 2010 .

[47] S. Njoya Motapon, L. Dessaint, and K. Al-Haddad, "A comparative study of energy management schemes for a fuel-cell hybrid emergency power system of more-electric aircraft," IEEE Transactions on Industrial Electronics, vol. 61, no. 3, pp. 13201334, 2014.

[48] P. García, J. P. Torreglosa, L. M. Fernández, and F. Jurado, "Viability study of a FC-battery-SC tramway controlled by 
equivalent consumption minimization strategy," International Journal of Hydrogen Energy, vol. 37, no. 11, pp. 9368-9382, 2012.

[49] K. B. Wipke, M. R. Cuddy, and S. D. Burch, "ADVISOR 2.1: a user-friendly advanced powertrain simulation using a combined backward/forward approach," IEEE Transactions on Vehicular Technology, vol. 48, no. 6, pp. 1751-1761, 1999.

[50] United States Environmental Protection Agency, "Dynamometer drive schedules," 2008, http://www.epa.gov/nvfel/testing/ dynamometer.htm. 


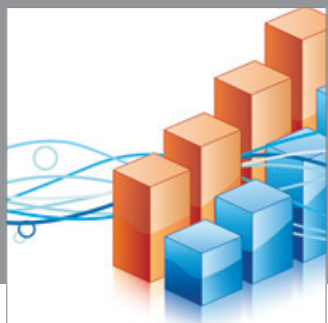

Advances in

Operations Research

mansans

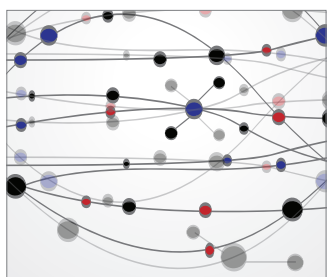

The Scientific World Journal
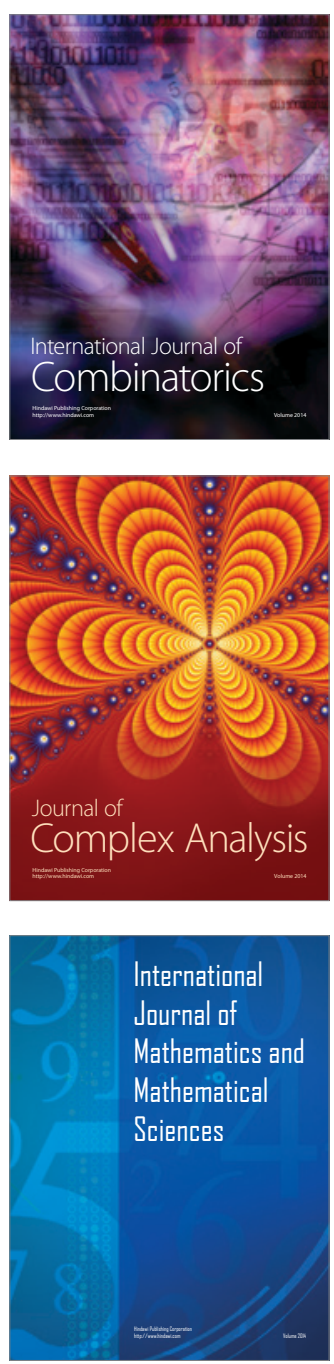
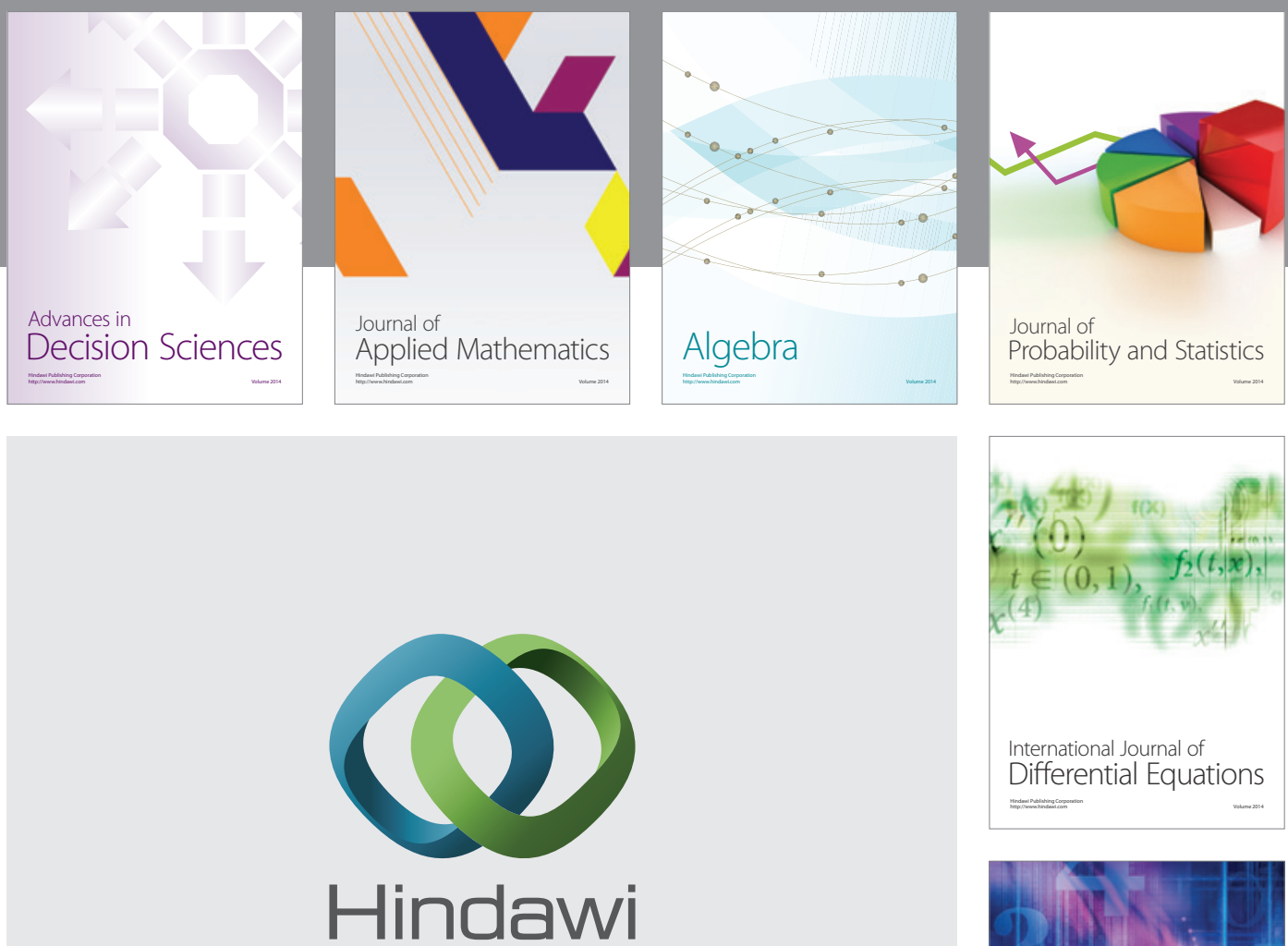

Submit your manuscripts at http://www.hindawi.com
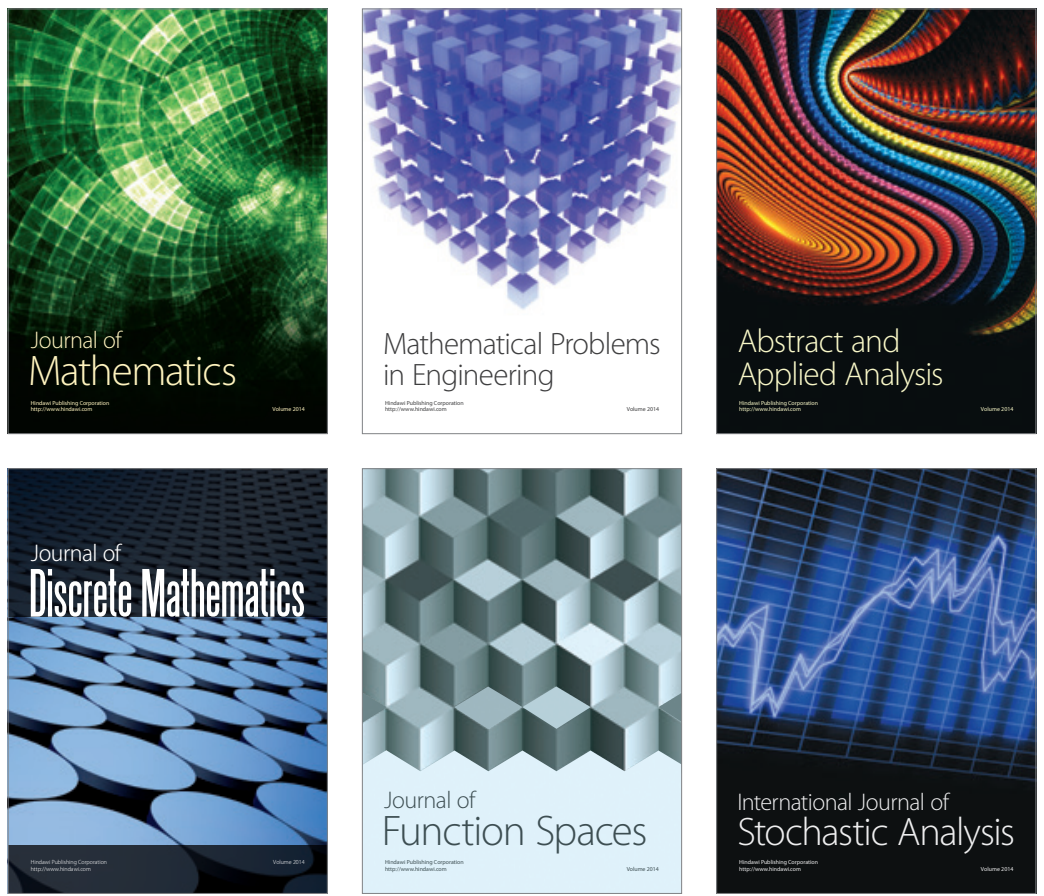

Journal of

Function Spaces

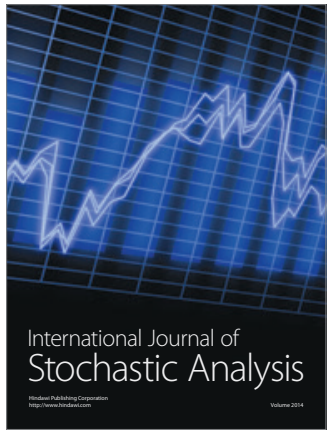

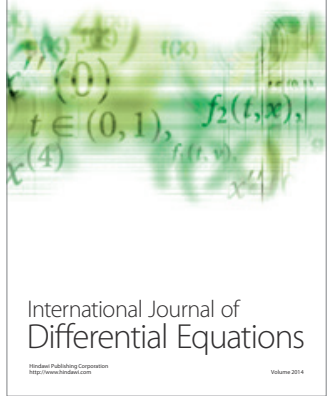
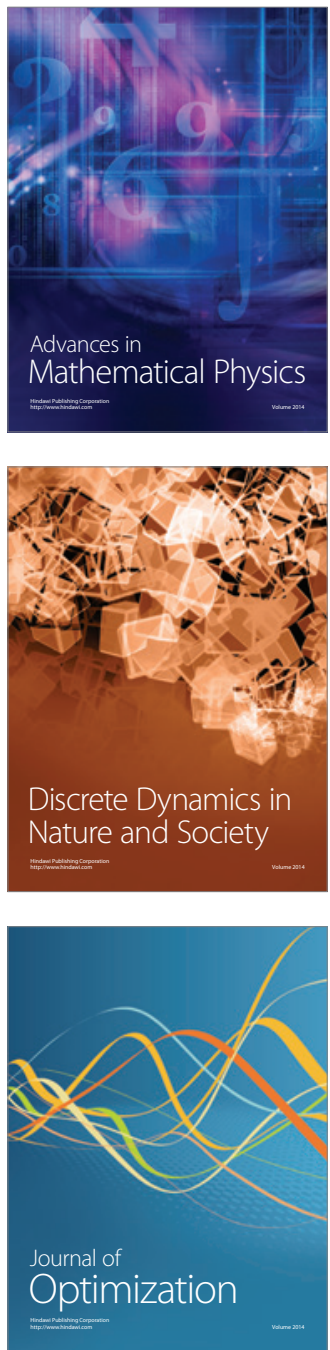